\title{
Comparative Study of the Accuracy of Different Techniques for the Laboratory Diagnosis of Schistosomiasis Mansoni in Areas of Low Endemicity in Barra Mansa City, Rio de Janeiro State, Brazil
}

\author{
Maria Cristina Carvalho Espírito-Santo, ${ }^{1,2}$ Mónica Viviana Alvarado-Mora, ${ }^{3}$ \\ Pedro Luiz Silva Pinto, ${ }^{4}$ Maria Carmen Arroyo Sanchez, ${ }^{5}$ Emmanuel Dias-Neto, ${ }^{6,7}$ \\ Vera Lúcia Pagliusi Castilho, ${ }^{8}$ Elenice Messias do Nascimento Gonçalves, ${ }^{8}$ \\ Pedro Paulo Chieffi, ${ }^{9,10}$ Expedito José de Albuquerque Luna, ${ }^{10}$ João Renato Rebello Pinho, ${ }^{3}$ \\ Flair José Carrilho, ${ }^{1}$ and Ronaldo Cesar Borges Gryschek ${ }^{1}$ \\ ${ }^{1}$ Department of Infectious and Parasitic Diseases and Laboratory of Immunopathology of Schistosomiasis (LIM-06), \\ School of Medicine, University of São Paulo, 05403-000 São Paulo, SP, Brazil \\ ${ }^{2}$ University Center of Volta Redonda, 27240-560 Volta Redonda, RJ, Brazil \\ ${ }^{3}$ Department of Gastroenterology and Laboratory of Tropical Gastroenterology and Hepatology, School of Medicine, \\ University of São Paulo, 05403-000 São Paulo, SP, Brazil \\ ${ }^{4}$ Department of Enteroparasites at the Parasitology and Mycology Service from the Adolfo Lutz Institute, \\ 01246-902 São Paulo, SP, Brazil \\ ${ }^{5}$ Laboratory of Seroepidemiology and Immunobiology, Institute of Tropical Medicine, University of São Paulo, \\ 05403-000 São Paulo, SP, Brazil \\ ${ }^{6}$ Laboratory of Medical Genomics, AC Camargo Cancer Center, 01509-010 São Paulo, SP, Brazil \\ ${ }^{7}$ Institute of Psychiatry (LIM-27), São Paulo Medical School, University of São Paulo, 01246-903 São Paulo, SP, Brazil \\ ${ }^{8}$ Section of Parasitology, Central Laboratory Division of Hospital das Clínicas, School of Medicine, University of São Paulo, \\ 05403-000 São Paulo, SP, Brazil \\ ${ }^{9}$ Santa Casa Medical School, 01221-020 São Paulo, SP, Brazil \\ ${ }^{10}$ Institute of Tropical Medicine, University of São Paulo, 05403-000 São Paulo, SP, Brazil
}

Correspondence should be addressed to Maria Cristina Carvalho Espírito-Santo; cristinasanto@usp.br

Received 2 March 2015; Revised 6 May 2015; Accepted 10 May 2015

Academic Editor: Stephan Karl

Copyright (c) 2015 Maria Cristina Carvalho Espírito-Santo et al. This is an open access article distributed under the Creative Commons Attribution License, which permits unrestricted use, distribution, and reproduction in any medium, provided the original work is properly cited.

\footnotetext{
Schistosomiasis constitutes a major public health problem, with an estimated 200 million people infected worldwide. Many areas of Brazil show low endemicity of schistosomiasis, and the current standard parasitological techniques are not sufficiently sensitive to detect the low-level helminth infections common in areas of low endemicity (ALEs). This study compared the Kato-Katz (KK); Hoffman, Pons, and Janer (HH); enzyme-linked immunosorbent assay- (ELISA-) IgG and ELISA-IgM; indirect immunofluorescence technique (IFT-IgM); and qPCR techniques for schistosomiasis detection in serum and fecal samples, using the circumoval precipitin test (COPT) as reference. An epidemiological survey was conducted in a randomized sample of residents from five neighborhoods of Barra Mansa, RJ, with 610 fecal and 612 serum samples. ELISA-IgM (21.4\%) showed the highest positivity and $\mathrm{HH}$ and $\mathrm{KK}$ techniques were the least sensitive (0.8\%). All techniques except qPCR-serum showed high accuracy (82-95.5\%), differed significantly from COPT in positivity $(P<0.05)$, and showed poor agreement with COPT. Medium agreement was seen with ELISA-IgG $(\mathrm{Kappa}=0.377)$ and IFA $($ Kappa $=0.347)$. Parasitological techniques showed much lower positivity rates than those by other techniques. We suggest the possibility of using a combination of laboratory tools for the diagnosis of schistosomiasis in ALEs.
} 


\section{Introduction}

Schistosomiasis is a major public health problem, with 200 million people infected worldwide and 700 million people residing in areas of infection risk [1,2].

In Brazil, schistosomiasis has been reported to occur in 19 states, and it is estimated that approximately 6 million people are infected and 25 million are at risk of contracting the disease. The national positivity rate is $6.94 \%$, ranging from $0.04 \%$ in Piauí State to $11.88 \%$ in Pernambuco State. In Rio de Janeiro State, the positivity rate is $1.56 \%$ [3].

Brazil has areas of different prevalence rates varying from state to state, as shown in Figure 1 [3].

Of the various known species of Schistosoma, S. mansoni has the widest global distribution and is the only species that causes schistosomiasis in Brazil [4].

Although the serious forms of schistosomiasis have become less prevalent, thanks mainly to the implementation of mass chemotherapy, the geographic expansion of schistosomiasis continues apace with the expansion of agricultural zones and irrigated areas [5].

The classification of the individual infection intensity criteria for S. mansoni is estimated by the quantity of eggs observed in parasitological examination of feces, using the Kato-Katz (KK) technique [2]. According to WHO, 2002 [6], the infection classification is high parasitic load ( $\geq 400$ epg), medium parasite load (100-399 epg), and low parasite load $(<100$ epg) and areas with high, medium, or low endemicity show prevalence of $\geq 50 \%, \geq 10 \%<50$, or $<10 \%$, respectively. In ALEs, approximately $75 \%$ of infected individuals are asymptomatic, show few symptoms, and have low parasite load, which hinders diagnosis [6].

The state of Rio de Janeiro presents the lowest number of confirmed cases and deaths due to schistosomiasis in the southeast region of Brazil [3,7]. The city of Barra Mansa is defined as microregion 2 of the Vale do Médio Paraíba, Rio de Janeiro State [8]. The city of Barra Mansa is located in the southern part of the state of Rio de Janeiro.

Barra Mansa is one of the foci of S. mansoni infection in the state of Rio de Janeiro [8]. The average prevalence was estimated to be $1 \%$, from 2001 to 2008 , based on the cases reported by the Notifiable Diseases Information System (SINAN) from 2001 to 2008 [9].

The endemic foci lie within the urban perimeter. The neighborhood of Siderlândia shows the highest prevalence, followed by the neighborhoods of Santa Clara, São Luiz, Cantagalo, and Nova Esperança. Isolated cases of infection by S. mansoni have been reported in further 30 neighborhoods [9].

Detection of S. mansoni eggs in feces has historically been used as the reference for diagnosing schistosomiasis, and Schistosoma species are identified by their characteristic morphology showing a lateral spicule. The parasitological methods are highly specific, inexpensive, and relatively simple to execute $[2,10-12]$. The Kato-Katz (KK) technique is most commonly used for detecting S. mansoni eggs in epidemiological studies, allowing the quantification of eggs in fecal samples. The Hoffman technique $(\mathrm{HH})$ is based on spontaneous sedimentation, and it is effective because



Positivity ranges (\%)

2003-2012

$<5$

$5-15$

$>15$

No data

FIGURE 1: Distribution of positivity ranges for schistosomiasis based on the record of cases on investigated cities, Brazil, 2012. Source: SISPCE-SVS/MS.

embryonated S. mansoni eggs are heavy; however, it is not suitable for quantification of eggs in feces.

Although these parasitological methods are inexpensive and simple to perform, they lack sensitivity, especially in ALEs [13-18]. The Secretariat of Health Vigilance in Brazil has proposed the elimination of this form of helminthiasis. Therefore, there is a need to define alternative laboratory diagnostic techniques for detection of S. mansoni in ALEs. Thus, the aim of this study was to compare the efficiency of existing parasitological, immunological, and molecular diagnostic methods in areas of low prevalence of S. mansoni, using the circumoval precipitin test (COPT) as a reference, due to its high sensitivity and specificity in ALEs $[19,20]$.

\section{Materials and Methods}

2.1. Study Design, Population, and Sample Size. S. mansoni is endemic in the city of Barra Mansa, Rio de Janeiro State, Brazil, with an estimated prevalence of 1\% [9]. Data for 2001-2008 from the Notifiable Diseases Information System (SINAN) showed that the disease is most prevalent in the neighborhoods of Siderlândia, Santa Clara, São Luiz, Nova 
Esperança, and Cantagalo, which belong to the Barra Mansa River Basin, a tributary of the Paraíba do Sul River. These five neighborhoods, located on the outskirts of the city of Barra Mansa, were selected for this cross-sectional study. Samples of feces and serum were collected from April to December 2011.

The sample size was calculated assuming a prevalence of $1 \%$, with an addition of $30 \%$ to compensate for losses. The estimated sample size required was 650 individuals residing in the above neighborhoods. Households were systematically selected (one in six), and individuals were randomly selected by a draw among those who agreed to participate in the study. Subjects who were older than 5 years of age and had not been treated for S. mansoni in the last year were eligible for inclusion.

2.2. Statistical Analysis. Statistical analysis was performed using SPSS (Statistical Package for the Social Sciences) for Windows, version 15.0 (SPSS Inc., Chicago, IL, USA) and Microsoft Excel 2003. Significance levels were fixed by accepting a Type 1 error of $5 \%(\alpha=0.05)$. Population characteristics were described using absolute and relative frequencies and calculation of mean ages and standard deviations. All participants were evaluated by each diagnostic technique.

Each S. mansoni infection measurement technique was compared and marginal associations were verified using McNemar's test. Pairwise concordance between results was assessed using Cohen's kappa index and 95\% confidence intervals. The Kappa index values range interpretation was as follows: poor agreement $(<0.20)$; low agreement $(0.20$ to $0.40)$; moderate agreement ( 0.41 to 0.60$)$; good agreement (0.61 to 0.80$)$; and very good agreement (0.81 to 1.00$)$ [21].

Associations between $S$. mansoni infection and age range, sex, neighborhood, river water use, and history of schistosomiasis were assessed for each technique using the Chi-square test, Fisher's exact, or likelihood ratio tests.

We compared the accuracy (sensitivity, specificity, likelihood ratio, and predictive values) of serological techniques to those of parasitological techniques. We also compared results among techniques to determine which were most effective in diagnosing $S$. mansoni in areas with a similar epidemiological profile to the target area of this study.

2.3. Ethical Aspects. In accordance with the rules governing human subject research, informed consent was obtained to meet the recommendations of Resolution $n^{\circ} 466$ from December 12, 2012, of the National Council of Health. This research project was approved by the Research Ethics Committee of the Department of Infectious and Parasitic Diseases of the Faculty of Medicine of the University of São Paulo and the Research Ethics Committee of the Hospital das Clínicas (CAPPesq) of the Faculty of Medicine of the University of São Paulo (Approval number 0405/09).

The experimental research procedures met Laws 6.638/79 and 9605/98, Decree 24.645/34, the Ethical Principles of Animal Experimentation, the Principles for Research Involving Animals [22], and other directives governing animal research. The study began after approval of research project number CEP-IMT 2011/096 by the Animal Ethics Research
Committee of the Institute of Tropical Medicine of São Paulo, University of São Paulo, Brazil.

2.4. Methods of Diagnostic Investigation. This was an interdisciplinary study, and the research laboratories developed their activities independently, following the conditions and operationalization timelines that respected the routine of each institute involved. Samples from all individuals in the study were subjected to the diagnostic techniques described and the reference diagnostic technique (COPT) [23]. The professionals who standardized and interpreted the COPT did not know the results for the diagnostic techniques, thus, reducing any interpretation bias.

The participating laboratories and the diagnostic techniques they developed were as follows: Municipal Secretary of Health of Barra Mansa/RJ (feces and serum collections); CentroLab Laboratory, Volta Redonda/RJ (preparing sample preanalysis); Institute Adolfo Lutz (COPT and ITF-IgM); Institute of Tropical Medicine/USP (ELISA); Laboratory of Gastroenterology and Tropical Hepatology at the Department of Gastroenterology/FMUSP (molecular biology), Research Center at A.C. Camargo Hospital (molecular biology), René Rachou Research Center/FIOCRUZ, Belo Horizonte/MG (molecular biology); Parasitological Section of the Central Laboratory, Division, HCFMU/SP (KK and HH).

The standardization and application of the diagnostic techniques were developed from December 2010 to December 2012, when the statistical analyses began.

2.5. Methods for Laboratory Diagnosis. The Family Health Program and health agents of the Municipal Schistosomiasis Control Program (PCE) collected 610 randomized fecal samples and 612 serum samples. Of these, 572 samples were paired, from inhabitants of 5 peripheral neighborhoods of Barra Mansa, Rio de Janeiro. The serum samples were aliquoted and stored at $-20^{\circ} \mathrm{C}$ and then transported to São Paulo in thermal boxes containing dry ice and stored at $-20^{\circ} \mathrm{C}$ in the lab until further testing.

2.6. Parasitological Methods. Stool samples were prepared following the KK (Helm Test, Bio-Manguinhos, Fiocruz, Rio de Janeiro, RJ, Brazil) and $\mathrm{HH}$ techniques and stored at $4^{\circ} \mathrm{C}$ until shipment. For the KK technique, two slides were prepared and stored in boxes fixed with a rigid polypropylene cover lined with cork (Prolab-Prolab, São Paulo, SP, Brazil). For the $\mathrm{HH}$ technique, samples were preserved in $10 \%$ formalin (Indalabor Indaiá Laboratório Farmacêutico Ltda., Dores do Indaiá, Minas Gerais, MG, Brazil), and two slides were prepared for each participant.

2.7. Laboratory Maintenance of the S. mansoni Experimental Cycle. The S. mansoni cycle was maintained through periodic infection of hamsters (Mesocricetus auratus) and Biomphalaria glabrata mollusks (strain BH). Each week, five animals were subcutaneously infected with 200-300 cercariae and sacrificed after 49 to 56 days to collect adult worms and parasite eggs. S. mansoni eggs were collected from liver granulomas. After washing with physiological solution 
for complete removal of blood, the worms and eggs were counted and frozen.

2.8. Adult Worm Total Extract. Approximately 10,000 S. mansoni adult worms of both sexes were thawed and resuspended at a concentration of approximately 1,000 worms $/ \mathrm{mL}$ in $10 \mathrm{mM}$ phosphate buffered saline (PBS), at $\mathrm{pH}$ 7.2. The protease inhibitor phenylmethylsulfonyl fluoride (PMSF, SigmaAldrich, St. Louis, MO, USA) was then added to produce a final concentration of $1 \mathrm{mM}$. The suspension was ground in a manual tissue homogenizer in an ice bath for $1 \mathrm{~h}$. After thorough mixing, the suspension was subjected to two centrifugations at $10,000 \times \mathrm{g}$, at $4^{\circ} \mathrm{C}$ for $45 \mathrm{~min}$. The supernatant was then removed, and the protein content was measured using the DC Protein Assay reagent (DetergentCompatible Colorimetric Assay Kit, Bio-Rad, Hercules, CA, USA) employing a modified Lowry method $[24,25]$. The extract was aliquoted and stored in a freezer at $-80^{\circ} \mathrm{C}$ until further use [26]. This total extract was used for the sensitization of microplates to IgG (ELISA-IgG) antibodies [27, 28].

2.9. TCA-Soluble Fraction. A soluble fraction in trichloroacetic acid (TCA-soluble fraction) was prepared from the crude extract of adult worms of S. mansoni, according to a previously described methodology [27], with modifications. An equal volume of $10 \%$ TCA was added to the total adult worm extract. After mixing vigorously for three cycles of $1 \mathrm{~min}$, using a vortexer (Vortex Genie-2, Scientific Industries Inc., Bohemia, NY, USA), the suspension was subjected to centrifugation at $10,000 \times \mathrm{g}$, at $4^{\circ} \mathrm{C}$ for $45 \mathrm{~min}$. The supernatant (containing the TCA-soluble fraction) was removed and then dialyzed against PBS on a cellulose membrane (SigmaAldrich) that retains substances with a molecular weight of $12,000 \mathrm{kDa}$ or greater, with continuous stirring overnight at $4^{\circ} \mathrm{C}$. We subsequently determined the protein content of the antigen solution (TCA-soluble fraction), which was then aliquoted and stored in a freezer at $-80^{\circ} \mathrm{C}$ until further use. The TCA-soluble fraction was used for the sensitization of microplates to IgM (ELISA-IgM) antibodies [26, 28].

2.10. Enzyme-Linked Immunosorbent Assays (ELISA). For ELISA-IgM, polystyrene plates (Costar High Binding 3590, Corning, NY, USA) were sensitized with $1 \mu \mathrm{g} /$ well of the TCA-soluble fraction of the $S$. mansoni total extract diluted in $0.1 \mathrm{M}$ carbonate/bicarbonate buffer ( $\mathrm{pH} 9.6$ ), incubating for $2 \mathrm{~h}$ at $37^{\circ} \mathrm{C}$, followed by $18 \mathrm{~h}$ at $4^{\circ} \mathrm{C}$ in a humid chamber. After washing three times with PBS containing $0.05 \%$ Tween20 (PBS-T), the plates were blocked for nonspecific sites with $200 \mu \mathrm{L}$ of $5 \%$ skim milk in PBS-T (PBS-TM 5\%), incubating for $2 \mathrm{~h}$ at $37^{\circ} \mathrm{C}$ in a humid chamber. The plates were then washed again with PBS-T. Serum samples were diluted (1:100) in PBS-T with 2\% skim milk (PBS-TM 2\%) and tested in duplicate $(50 \mu \mathrm{L} /$ well $)$. After incubation, for $30 \mathrm{~min}$ at $37^{\circ} \mathrm{C}$ in a humid chamber, the plates were washed three times with PBS-T, and $50 \mu \mathrm{L}$ of a $\mu$-chain-specific anti-human IgM peroxidase conjugate (Sigma-Aldrich) diluted 1: 5000 in PBSTM $2 \%$ was added. After 30 min of incubation in a humid chamber, the plates were washed with PBS-T, and $100 \mu \mathrm{L}$ of

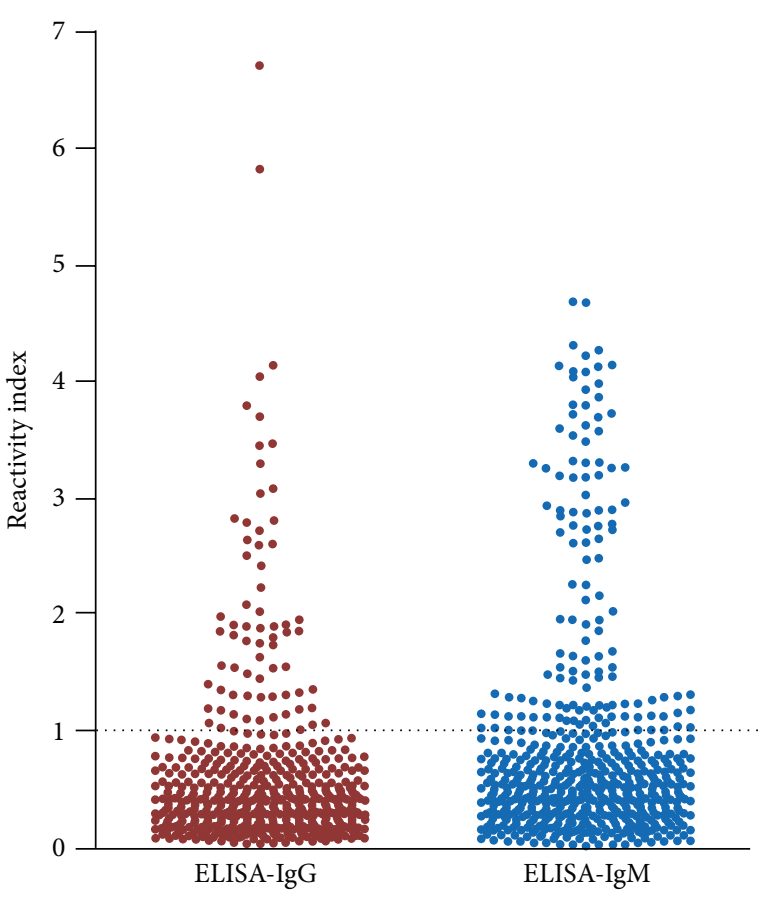

FIGURE 2: Reactivity index of 612 sera obtained by ELISA-IgG and IgM-ELISA technique of the individuals in the city of Barra Mansa, RJ, Brazil, 2011.

a chromogenic mixture consisting of tetramethylbenzidine (TMB) and $\mathrm{H}_{2} \mathrm{O}_{2}$ was added. After 10 min of incubation in the dark, the reaction was quenched with $25 \mu \mathrm{L}$ of $2 \mathrm{~N} \mathrm{H}_{2} \mathrm{SO}_{4}$. The absorbance at $450 \mathrm{~nm}$ was measured using an ELISA plate reader (Titertek Multiskan MCC/340, Lab Systems, Helsinki, Finland).

The reaction conditions described above for performing ELISA-IgM testing were also used for ELISA-IgG testing, except that polystyrene plates (Nunc PolySorp, Roskilde, Denmark), a $500 \mathrm{ng} /$ well total antigen extract of $S$. mansoni, and an Fc-specific anti-human IgG peroxidase conjugate (Sigma-Aldrich) diluted 1:20,000 were used.

To determine the threshold of reactivity (cut-off) for ELISA-IgG and ELISA-IgM, receiver operating characteristic (ROC) curves were constructed. We used 13 and 29 samples from patients who tested positive and negative, respectively, for S. mansoni in the parasitological examination and IFT, and 13 samples from patients who tested positive for other helminth parasites in the parasitological examination and negative for S. mansoni in IFT.

The reactivity index (RI) of the samples was calculated using the equation IR = sample absorbance/cut-off. Serum samples with IR $\geq 1.00$ were considered reactive, Figure 2 .

2.11. Detection of IgM Antibodies against Antigens of the $S$. mansoni Digestive Tract. IFT-IgM was used to detect antiantigen polysaccharide $\operatorname{IgM}$ antibodies in the digestive tract of adult $S$. mansoni worms on paraffin sections, according to the technique described by Silva et al. [29] and Nash, 1974 [30] and 1978 [31]. 
2.12. Obtaining Adult Worms. The infected hamsters were anesthetized with an intramuscular injection of $100 \mathrm{mg} / \mathrm{kg}$ of ketamine and xylazine and sacrificed, following the animal sacrifice guidelines of our institution. After sectioning the portal vein, $50 \mathrm{~mL}$ of $0.85 \%$ saline solution with ethylenediaminetetraacetic acid (EDTA) was infused in the left ventricle using a $20 \mathrm{~mL}$ syringe, through successive infusions, by not having an infusion pump for maintaining a continuous flow. Adult worms were obtained after perfusion of the portal system, removed from the abdominal cavity, and numbered and stored at $-20^{\circ} \mathrm{C}$. Adult male worms were separated for "particulate" antigen processing in paraffin sections for IFTIgM analysis.

2.13. Slide Preparation for IFT-IgM. Approximately 60 adult male worms were placed on an end-jointed $200 \mu \mathrm{L}$ mesh screen (Tecmolin, PA-6-212/XX, São Paulo, SP, Brazil), immersed in Rossman's solution fixative for $2 \mathrm{~h}$ at room temperature and then immersed in 90\% ethanol three times for $2 \mathrm{~h}$. The samples were then immersed in absolute alcohol for $15 \mathrm{~h}$ and incubated in methyl benzoate for $4 \mathrm{~h}$, xylol at $60^{\circ} \mathrm{C}$ for $15 \mathrm{~min}, 50 \%$ xylene/paraplast for $15 \mathrm{~min}$, and $100 \%$ paraplast (Monjet Scient.) at $60^{\circ} \mathrm{C}$ for $30 \mathrm{~min}$. The material was embedded in an L-shaped aluminum frame, placed at room temperature for $12 \mathrm{~h}$, and subsequently stored at the same temperature for processing of histological sections. Serial sections of $5 \mu \mathrm{m}$ thickness were cut using a microtome, at ten sections per slide.

The slides containing paraffin sections were subjected to dewaxing and rehydration, using successive baths of xylene and ethanol at different concentrations, with a final bath in $\mathrm{PBS}, \mathrm{pH}=7.2$. The slides were stored at room temperature until use.

2.14. IFT-IgM. Serum samples were diluted 1:10 in PBS solution ( $\mathrm{pH}$ 7.2) and deposited on the paraffined sections of adult worms. After incubation at $37^{\circ} \mathrm{C}$ for $50 \mathrm{~min}$ in a humid chamber, slides were washed in $0,01 \mathrm{M}$ PBS ( $\mathrm{pH}$ 7.2) baths for $10 \mathrm{~min}$. Anti-human IgM fluorescent conjugate (goat anti-human IgG $\gamma$-chain-specific fluorescein isothiocyanate antibody) was added (Sigma-Aldrich; St. Louis, MO, USA) in accordance with its optimal use titer $(1 / 320)$ in $\mathrm{PBS}, \mathrm{pH}=$ 7.2 containing 1\% Evans blue solution (Bio-Rad Laboratories, Washington, DC, USA). After further incubation and washes, slides were dried and mounted with glycerol and coverslips. Positive standard serum was used for $1 / 10,1 / 40$, and $1 / 160$ dilutions. Negative standard serum was used for $1 / 10$ dilutions.

The IFT-IgM reading was performed using an Olympus BX-FLA fluorescence microscope (Olympus Corporation, Tokyo, Japan) equipped with an epi-illumination system, with 100x and/or 200x magnification.

A sample was considered positive when fluorescence was present only in structures related to the parasite digestive tract (Figure 3). Fluorescence detected in membranes or parasite parenchyma was considered nonspecific. The results were expressed as reactive (presence of fluorescence in the digestive tract) and nonreactive (absence of fluorescence) sera.

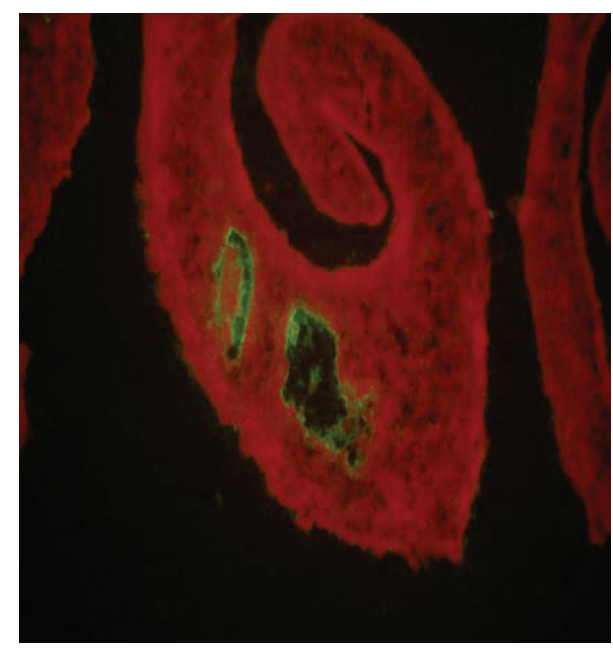

FIGURE 3: Reactivity of the inner lining of the digestive tube: positive human serum IgM antibodies.

The classification of the sera was based on the fluorescence intensity in the internal portion of the worms digestive tract (only male worms were used for embedment), according to a targeted fluorescence intensity scale. The attribution of $1+$ to $4+$ was obtained comparing the results with a photographic standard built with serum: nonreactive (0), low (1+), medium $(2+)$, strong $(3+)$, and very strong $(4+)$.

2.15. Antibody Detection of S. mansoni Egg Antigens. Circumoval precipitin test (COPT) was used to detect antibody reactions against excretion and secretion products of $S$. mansoni eggs, using previously described techniques [32].

2.16. Isolation and Purification of S. mansoni Eggs. S. mansoni eggs were isolated and purified as described by Dresden and Payne [33] and Pinto et al. [34] with some modifications.

Livers from three infected hamsters were cut into small pieces $(3 \mathrm{~mm})$ and incubated in a water bath at $37^{\circ} \mathrm{C}$ for $20 \mathrm{~min}$, in a solution containing $0.004 \%$ pepsin and $0.7 \%$ hydrochloric acid. After incubation, the peptic solution was discarded and the tissue fragments were added to $150 \mathrm{~mL}$ of $0.9 \%$ ice-cold saline solution containing $50 \mu \mathrm{L}$ of Triton $\mathrm{X}-100$. The material was homogenized using several drive pulses in a domestic blender (Walita Philips, Amsterdam, Netherlands) until the fragments were completely ruptured. The material was then filtered in fourfold gauze and screen processed under negative pressure through a series of metallic sieves with mesh numbers $100(0.150 \mathrm{~mm}), 200(0.075 \mathrm{~mm})$, and $400(0.038 \mathrm{~mm})$ (Granutest, Telastem, Peneiras Para Análise Ltda., São Paulo, SP, Brazil).

Eggs retained on the last sieve were removed by successive washing with ice-cold $0.9 \%$ saline solution and concentrated to $1 \mathrm{~mL}$ volume by centrifugation at $154 \times \mathrm{g}$ for $15 \mathrm{sec}$. From this concentrated suspension, a $10 \mu \mathrm{L}$ aliquot was placed between the blade and the coverslip and evaluated under a microscope (Olympus Corporation, Tokyo, Japan) at $100 \mathrm{x}$ magnification. The number of eggs under the entire area 


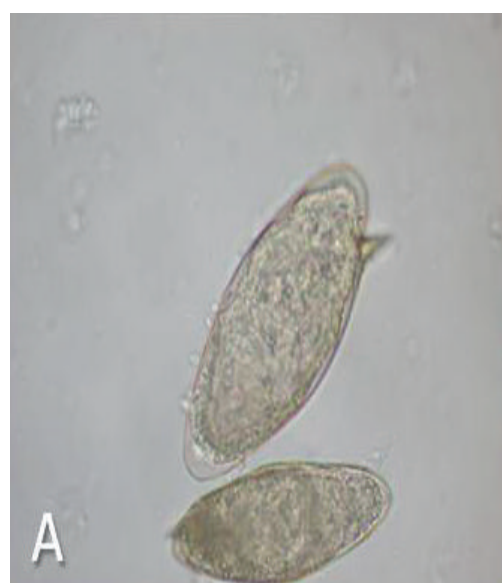

(a)

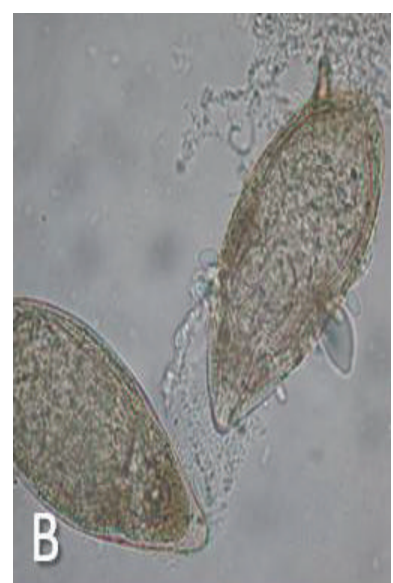

(b)



(c)

FIGURE 4: Intensity patterns of RPO: (a) RPO pattern 1; (b) RPO pattern 2; (c) RPO pattern 3.

of the coverslip was counted. Suspensions exceeding 20\% cell debris in relation to the number of eggs found were reprocessed through the 200 and 400 mesh sieves. For COPT, the egg suspensions were adjusted to contain 300 viable eggs per $10 \mu \mathrm{L}$ of $0.9 \%$ saline solution and stored at $4^{\circ} \mathrm{C}$ for $4 \mathrm{~h}$ until reaction preparation.

2.17. Circumoval Precipitin Test. Aliquots $(10 \mu \mathrm{L})$ of each purified egg suspension, adjusted to contain 300 viable eggs in $0.9 \%$ saline solution, and $50 \mu \mathrm{L}$ of each serum sample, were added to $2 \mathrm{~mL}$ Eppendorf tubes (Eppendorf do Brasil Ltda., São Paulo, SP, Brazil) and incubated at $37^{\circ} \mathrm{C}$ for $48 \mathrm{~h}$. Subsequently, a $30 \mu \mathrm{L}$ aliquot of each mixture (serum + viable egg suspension) was placed on a slide and covered with a coverslip $(22 \times 22 \mathrm{~mm})$. Assessment was performed on a binocular Olympus-CX41 microscope (Olympus Corporation, Tokyo, Japan), with a $10 x$ or $40 x$ objective lens. The number of reactive eggs per 100 viable eggs and the periovular precipitate morphology were used for assessment. S. mansoni eggs were considered reactive if they contained globular precipitates of variable size and form, or if they appeared as small or long septated chains, similar to Taenia segments (Figure 4). Sera were considered positive if at least $9 \%$ of the mature eggs were reactive in the presence of different precipitates [35].

2.18. TaqMan Real-Time PCR Assays. Preanalysis preparation of feces samples for qPCR. Fecal samples, without conservatives, were passed through a Nylon Baltex PA-7-200/XX filter (Tecmolin, São Paulo, SP, Brazil) to remove larger impurities. Using a marked stainless steel measuring plate, approximately $500 \mathrm{mg}$ of feces from each sample was aliquoted and stored in a freezer at $-20^{\circ} \mathrm{C}$.

2.19. DNA Extraction from Serum. DNA was extracted from hamster serum samples and the $0.9 \%$ saline solution containing 200 eggs $/ \mathrm{mL}$, using the guanidine isothiocyanate-phenolchloroform (GT) method [36, 37]. DNA was stored at $-20^{\circ} \mathrm{C}$ after extraction.
2.20. DNA from Fecal Samples. DNA extraction from hamster feces was performed in two phases: in the first phase, after resuspending approximately $500 \mathrm{mg}$ of stool in $1 \mathrm{~mL}$ $0.1 \mathrm{M}$ PBS, five glass beads were added. This mixture was homogenized for $5 \mathrm{~min}$ using a vortex mixer, followed by centrifugation for $8 \mathrm{~min}$ at $16.863 \times \mathrm{g}$ at $4^{\circ} \mathrm{C}$. An aliquot of $400 \mu \mathrm{L}$ of the supernatant was mixed with $100 \mu \mathrm{L}$ of Rapid One-Step Extraction (ROSE) solution: $10 \mathrm{mM}$ Trishydroxymethyl amino methane $\mathrm{HCl}, \mathrm{pH} 8 ; 300 \mathrm{mM}$ EDTA, $\mathrm{pH} 8.0 ; 1 \%$ sodium lauroyl sarcosinate (Sarkosyl); and $1 \%$ polyvinylpolypyrrolidone (PVPP) [38]. Then, $30 \mu \mathrm{L}$ of Proteinase K (Life Technologies, Carlsbad, CA, USA) was added and homogenized using a vortex mixer. The sample was incubated for $120 \mathrm{~min}$ at $65^{\circ} \mathrm{C}$. In the second phase, the DNA present in this solution was extracted and stored as described for serum samples.

2.21. Purification of DNA Extracted from Fecal and Serum Samples. DNA extracted from serum and feces, at distinct times after infection, was purified using the InstaGene Matrix in accordance with the manufacturer's instructions. Once purified, extracted DNA was stored at $-20^{\circ} \mathrm{C}$ until use.

\subsection{Amplification of DNA from Serum and Fecal Samples}

Primers and Probes. A set of primers and probes complementary to a $121 \mathrm{bp}$ tandem repeat sequence from $S$. mansoni strain SM 1-7 (GenBank accession number M61098), described by Hamburger et al. [39], were used for amplification and detection of $S$. mansoni DNA. Primer sequences were as follows: forward F2: $5^{\prime}$-CCG ACC AAC CGT TCT ATG A-3'; reverse R2: $5^{\prime}$-CAC GC TCT CGC AAA TAA TCT AAA-3 ${ }^{\prime}$; probe PO2: $5^{\prime}-6[\mathrm{FAM}]$ TCG TTG TAT CTC CGA AAC CAC TGG ACG [(BHQ1])-3'; all probes were synthesized by Sigma Life Sciences (Woodlands, TX, USA).

All samples were evaluated using TaqMan Reagents Exogenous Internal Positive Control (IPC) (Life Technologies), in accordance with the manufacturer's instructions to test for the presence of Taq DNA polymerase inhibitors. 
For the positive control of the qPCR-feces, in all assays, we used DNA obtained in the extraction of $200 \mathrm{eggs} / \mathrm{mL}$ of saline $0.9 \%$.

\subsection{TaqMan Real-Time PCR Conditions for Serum and Fecal} Samples. TaqMan Real-Time PCR was performed in a final volume of $20 \mu \mathrm{L}$ containing $10 \mu \mathrm{L}$ TaqMan Universal PCR Master Mix 2X, 20 pmol of primers F2 and R2, 5 pmol of the $\mathrm{PO} 2$ probe, and $2 \mu \mathrm{L}$ of purified DNA. For each sample, another reaction was performed in parallel using the TaqMan Reagents Exogenous Internal Positive Control (IPC) in a final volume of $21 \mu \mathrm{L}$, containing $10 \mu \mathrm{L}$ of TaqMan Universal PCR Master Mix 2X, $5 \mu \mathrm{L} 10 \mathrm{X}$ Exogenous IPC mix, $1 \mu \mathrm{L}$ $50 \mathrm{X}$ Exo IPC, and $5 \mu \mathrm{L}$ of purified DNA samples. For each batch of reactions, two additional controls were used: a no amplification control (NAC) and a no template control target (NCT). PCR was performed in an Applied Biosystems 7300 Real-Time PCR System (Life Technologies) using the following cycling conditions: $50^{\circ} \mathrm{C}$ for $2 \mathrm{~min}$; $95^{\circ} \mathrm{C}$ for $10 \mathrm{~min}$; and 40 cycles at $95^{\circ} \mathrm{C}$ for $15 \mathrm{sec}$ and $60^{\circ} \mathrm{C}$ for $1 \mathrm{~min}$.

To detect S. mansoni, the Applied Biosystems 7300 RealTime PCR System standard cycles were used: $50^{\circ} \mathrm{C}$ for $2 \mathrm{~min}$; $95^{\circ} \mathrm{C}$ for $10 \mathrm{~min} ; 40$ cycles at $95^{\circ} \mathrm{C}$ for $15 \mathrm{sec}$, and $60^{\circ} \mathrm{C}$ for $1 \mathrm{~min}$.

For the positive control of the qPCR-serum, in all assays, we used DNA obtained in the extraction of $200 \mathrm{eggs} / \mathrm{mL}$ of saline $0.9 \%$.

Furthermore, the possibility of contamination was minimized by performing DNA extraction and amplification in separate rooms, by performing all experiments inside a laminar flow cabinet, by frequent use of ultraviolet (UV) (Bio II A-Telstar, Life Science, Vancouver, Canada) irradiation, and by using only disposable, sterile laboratory equipment and pipette tips with filters.

2.24. Criteria Used to Evaluate the Results of qPCR Using Stool and Serum Samples. The following criteria were used to evaluate the qPCR:

Positive qPCR: duplicates of the sample were amplified by $\mathrm{qPCR}$.

Undetermined qPCR: one aliquot of the sample was amplified by qPCR.

qPCR IPC: exogenous control for the testing sample was not amplified (negative) by qPCR.

The undetermined qPCR and qPCR IPC samples were tested in triplicate. Duplicate amplifications of the samples obtained by qPCR were included in the positive results [38].

\section{Results}

The characteristics of the sample population (650 freely participating individuals) residing in the five suburbs of the city of Barra Mansa (RJ), used to evaluate the techniques ELISAIgG, ELISA-IgM, ITF-IgM, COPT, qPCR-serum, qPCR-feces, $\mathrm{KK}$, and $\mathrm{HH}$, are shown in Table 1.

Analysis of Table 1 reveals that the majority of the individuals were female with an average age of 39.7. The greatest
TABLE 1: Sociodemographic characteristics of the study population, individuals from the city of Barra Mansa, RJ, 2011.

\begin{tabular}{|c|c|c|}
\hline Characteristic & Frequency & $\%$ \\
\hline \multicolumn{3}{|l|}{ Sex } \\
\hline Female & 385 & 59.2 \\
\hline Male & 265 & 40.8 \\
\hline \multicolumn{3}{|l|}{ Age group (years) } \\
\hline 1 to 9 & 27 & 4.2 \\
\hline 10 to 19 & 144 & 22.2 \\
\hline 20 to 49 & 250 & 38.5 \\
\hline 50 or over & 229 & 35.2 \\
\hline Average age (SD) & $39.7(21.1)$ & \\
\hline \multicolumn{3}{|l|}{ Literacy } \\
\hline Yes & 624 & 96.0 \\
\hline No & 22 & 3.4 \\
\hline Not reported & 4 & 0.6 \\
\hline \multicolumn{3}{|l|}{ Neighborhood } \\
\hline Cantagalo & 47 & 7.2 \\
\hline Nova Esperança & 187 & 28.8 \\
\hline Santa Clara & 35 & 5.4 \\
\hline São Luiz & 102 & 15.7 \\
\hline Siderlândia & 279 & 42.9 \\
\hline \multicolumn{3}{|l|}{ Water supply } \\
\hline General network & 551 & 84.8 \\
\hline Well or spring & 79 & 12.2 \\
\hline Others & 1 & 0.2 \\
\hline Not reported & 19 & 2.9 \\
\hline \multicolumn{3}{|l|}{ Use of river water } \\
\hline No & 473 & 72.8 \\
\hline Washing clothes & 15 & 2.3 \\
\hline Washing utensils & 2 & 0.3 \\
\hline Baths & 5 & 0.8 \\
\hline Swimming & 5 & 0.8 \\
\hline Sand extraction & 7 & 1.1 \\
\hline Not reported & 143 & 22.0 \\
\hline \multicolumn{3}{|c|}{ Destination of feces and urine } \\
\hline Sewer system & 486 & 74.8 \\
\hline Septic tank & 7 & 1.1 \\
\hline In the open & 117 & 18.0 \\
\hline Not reported & 40 & 6.2 \\
\hline \multicolumn{3}{|c|}{ Previous schistosomiasis } \\
\hline Yes & 25 & 3.8 \\
\hline No & 519 & 79.8 \\
\hline Not reported & 106 & 16.3 \\
\hline
\end{tabular}

number of participants resided in the neighborhood of Sinderlândia (42.9\%) and approximately $4 \%$ of the participants reported a history of schistosomiasis.

The positivity for infection by S. mansoni according to each diagnostic technique used in this study is shown in Table 2.

The technique that presented most evidence of infection by $S$. mansoni was the ELISA-IgM (21.4\%), whereas 
TABle 2: Positivity for infection by $S$. mansoni, according to diagnostic technique, in samples collected from individuals in the city of Barra Mansa, RJ, 2011.

\begin{tabular}{lcc}
\hline Technique & Positive/total & $\%$ \\
\hline KK-HH & $5 / 610$ & 0.8 \\
ELISA-IgG & $71 / 612$ & 11.6 \\
ELISA-IgM & $131 / 612$ & 21.4 \\
COPT & $33 / 612$ & 5.4 \\
ITF-IgM & $97 / 612$ & 15.8 \\
qPCR-feces & $60 / 610$ & 9.8 \\
qPCR-serum & $9 / 612$ & 1.5 \\
\hline
\end{tabular}

TABLE 3: Prevalence of schistosomiasis mansoni and other enteroparasites, as determined using the $\mathrm{KK}$ and $\mathrm{HH}$ techniques in individuals from the city of Barra Mansa, RJ, 2011.

\begin{tabular}{lcc}
\hline Parasitosis HH/KK & Frequency & $\%$ \\
\hline Schistosoma mansoni & 5 & 0.8 \\
Endolimax nana & 106 & 17.4 \\
Entamoeba coli & 28 & 4.6 \\
Entamoeba hartmanni & 1 & 0.2 \\
Entamoeba histolytica/dispar & 5 & 0.8 \\
Blastocystis spp./hominis & 66 & 10.8 \\
Giardia lamblia/intestinalis & 11 & 1.8 \\
Iodamoeba butschlii & 1 & 0.2 \\
Enterobius vermicularis & 6 & 1.0 \\
Strongyloides stercoralis & 9 & 1.5 \\
Ascaris lumbricoides & 4 & 0.7 \\
Trichuris trichiura & 3 & 0.5 \\
Taenia sp. & 2 & 0.3 \\
\hline
\end{tabular}

the parasitological techniques ( $\mathrm{KK}$ and $\mathrm{HH}$ ) showed the lowest rates of infection $(0.8 \%)$.

In the KK technique, the quantity of eggs detected per gram of feces varied from 0 to 456 eggs. One of the five positive cases was diagnosed only with the $\mathrm{HH}$ technique.

The prevalence of infection with $S$. mansoni and various enteroparasites diagnosed by the $\mathrm{KK}$ and $\mathrm{HH}$ techniques in individuals from the city of Barra Mansa/RJ, 2011, is shown in Table 3.

Of the individuals tested, $27.9 \%$ were found to be infected with at least one parasite.

The results of the KK technique showed low positivity for any diagnosed parasitosis, and the positivity rate for infection by $S$. mansoni was $0.7 \%(n=4)$.

The ELISA-IgG reactivity index showed an average of 2.12, with an SD of 1.10 (median $=1.85$; minimum $=1.01$; maximum $=6.72 ; n=71$ ). The ELISA-IgM reactivity index showed an average of 2.24, with an SD of 1.09 (median $=1.91$; minimum $=1.02$; maximum $=4.67 ; n=131$ ). The IFT-IgM positivity showed an average of 1.56 crosses, with an SD of 0.69 (median $=1$; minimum $=1$; maximum $=3 ; n=97$ ). COPT reactivity was observed in an average of $21 \%$ of viable eggs, with an SD of $9 \%$ (median $21 \%$ viable eggs; minimum = $9 \%$ viable eggs; maximum $38 \%$ viable eggs; $n=33$ ).
Table 4 shows that the results of the qPCR technique that were positive (Figure 6) and undetermined occurred with a frequency of $9.8 \%$ and $8.9 \%$ and a median of 34.8 and 37.1 , respectively.

In this study, we found that in $16.2 \%(n=99)$ of the fecal samples amplification of the exogenous control (IPC) and $S$. mansoni DNA was unsuccessful.

In serum samples (Table 5), the Ct values of the qPCR positive (Figure 6) and undetermined samples were 1.5\% ( $n$ $=9)$ and $5.1 \%(n=31)$ and the median was 36.3 and 37.0 , respectively.

Table 6 shows that the positivity rate of the COPT technique differed significantly from all other techniques; it showed a lower positivity rate than the ELISA-IgG, ELISA$\operatorname{IgM}$, IFT-IgM $(P<0.001)$, and qPCR-feces $(P=0.001)$ techniques and a higher positivity rate than the $\mathrm{KK}, \mathrm{HH}$, and qPCR-serum techniques $(P<0.001)$. The results of the COPT technique presented greater concordance with those from ELISA-IgG $(\mathrm{Kappa}=0.377)$, IFT-IgM $($ Kappa $=0.347)$, and qPCR-feces (Kappa $=0.311)$ techniques.

When comparing COPT with the other diagnostic techniques, ELISA-IgM assay presented the highest sensitivity (Table 7).

\section{Discussion}

Diagnosis of S. mansoni is challenging, and determining the prevalence of infection is therefore difficult. Schistosomiasis is a chronic infection that may not progress to a severe form but that can trigger debilitating sequelae that are secondary to parasitism. This is particularly true in children, who may experience delayed growth and develop anemia and chronic malnutrition [2]. Moreover, asymptomatic carriers can potentially transmit schistosomiasis in areas that lack adequate sanitation [40].

Because of the present state of endemism of schistosomiasis in Brazil, the current proposal is the interruption (elimination) of its transmission. Thus, there is a need to develop new techniques that are more sensitive and specific, to permit early diagnosis and treatment of infected individuals, necessary for the control of this helminthiasis [3].

In this study, we compared the performance of the KK and $\mathrm{HH}$ techniques, the ELISA-IgG, ELISA-IgM, and the ITFIgM techniques, as well as qPCR of stool and serum samples, using the COPT technique as a reference $[19,20,41]$.

The positivity rate for schistosomiasis in our study population, as determined by immunological techniques, ranged from $21.4 \%(131 / 612)$ for ELISA-IgM to $15.8 \%$ (97/612) for ITF-IgM and $11.6 \%(71 / 612)$ for ELISA-IgG. These rates are above those for parasitological techniques to diagnose $S$. mansoni infection. The low sensitivity of the parasitological method in ALEs had previously been described [13-18, 28, $42,43]$.

The high positivity rates observed in this study for the ELISA-IgG, ELISA-IgM, and ITF-IgM techniques could have been caused by inclusion of individuals previously infected by $S$. mansoni, but properly treated and cured, or inclusion of those that were exposed to very small loads of cercariae 
TABLE 4: Results from the positive and undetermined qPCRs, with the threshold cycle (Ct) values, in fecal samples from the population of the city of Barra Mansa, RJ, 2011.

\begin{tabular}{|c|c|c|c|c|c|c|c|}
\hline \multirow{2}{*}{ Technique } & \multirow{2}{*}{ Cases/total } & \multirow{2}{*}{$\%$} & \multicolumn{5}{|c|}{ Ct values (LOG) qPCR } \\
\hline & & & Average & SD & Median & Minimum & Maximum \\
\hline qPCR positive & $60 / 610$ & 9.8 & 33.6 & 4.9 & 34.8 & 14.7 & 38.8 \\
\hline qPCR undetermined & $54 / 610$ & 8.9 & 32.3 & 8.5 & 37.1 & 11.5 & 40.0 \\
\hline
\end{tabular}

TABLE 5: Description of the threshold cycle (Ct) for the results from the positive and undetermined qPCR in serum samples from the individuals sampled from the city of Barra Mansa, RJ, 2011.

\begin{tabular}{lcccccccc}
\hline \multirow{2}{*}{ Sample } & \multirow{2}{*}{ Technique } & \multirow{2}{*}{ Cases/total } & \multirow{2}{*}{} & & \multicolumn{4}{c}{ Ct values (LOG) qPCR } \\
& & & & Average & SD & Median & Minimum & Maximum \\
\hline \multirow{2}{*}{ Serum } & qPCR positive & $9 / 612$ & 1.5 & 36.9 & 1.3 & 36.3 & 38.8 & 35.2 \\
& qPCR undetermined & $31 / 612$ & 5.1 & 35.5 & 4.4 & 37 & 39.7 \\
\hline
\end{tabular}

TABLE 6: Concordance between the positive results obtained using the COPT technique and those obtained using the other techniques, in fecal and serum samples collected from the sample population in the city of Barra Mansa, RJ, 2011.

\begin{tabular}{|c|c|c|c|c|c|c|c|}
\hline \multirow{3}{*}{ Techniques } & \multicolumn{2}{|c|}{$\mathrm{COPT}$} & \multirow{3}{*}{$\begin{array}{l}\text { Total } \\
n(\%)\end{array}$} & \multirow{3}{*}{$P$ McNemar } & \multirow{3}{*}{ Kappa } & \multicolumn{2}{|c|}{ IC (95\%) } \\
\hline & Negative & Positive & & & & & \\
\hline & $n(\%)$ & $n(\%)$ & & & & Lower & Higher \\
\hline \multicolumn{8}{|l|}{ KK-HH } \\
\hline Negative & $542(94.8)$ & $25(4.4)$ & 567 (99.1) & \multirow{3}{*}{$<0.001$} & \multirow{3}{*}{0.224} & \multirow{3}{*}{0.038} & \multirow{3}{*}{0.409} \\
\hline Positive & $1(0.2)$ & $4(0.7)$ & $5(0.9)$ & & & & \\
\hline Total & $543(94.9)$ & $29(5.1)$ & $572(100.0)$ & & & & \\
\hline \multicolumn{8}{|l|}{ ELISA-IgG } \\
\hline Negative & $530(86.6)$ & $11(1.8)$ & $541(88.4)$ & \multirow{3}{*}{$<0.001$} & \multirow{3}{*}{0.377} & \multirow{3}{*}{0.255} & \multirow{3}{*}{0.500} \\
\hline Positive & $49(8.0)$ & $22(3.6)$ & $71(11.6)$ & & & & \\
\hline Total & $579(94.6)$ & $33(5.4)$ & $612(100.0)$ & & & & \\
\hline \multicolumn{8}{|l|}{ ELISA-IgM } \\
\hline Negative & $475(77.6)$ & $6(1)$ & $481(78.6)$ & \multirow{3}{*}{$<0.001$} & \multirow{3}{*}{0.266} & \multirow{3}{*}{0.178} & \multirow{3}{*}{0.354} \\
\hline Positive & $104(17.0)$ & $27(4.4)$ & $131(21.4)$ & & & & \\
\hline Total & $579(94.6)$ & $33(5.4)$ & $612(100.0)$ & & & & \\
\hline \multicolumn{8}{|l|}{ IFT-IgM } \\
\hline Negative & $508(83.0)$ & $7(1.1)$ & $515(84.2)$ & \multirow{3}{*}{$<0.001$} & \multirow{3}{*}{0.347} & \multirow{3}{*}{0.241} & \multirow{3}{*}{0.454} \\
\hline Positive & $71(11.6)$ & $26(4.2)$ & $97(15.8)$ & & & & \\
\hline Total & $579(94.6)$ & $33(5.4)$ & $612(100.0)$ & & & & \\
\hline \multicolumn{8}{|l|}{ qPCR-feces } \\
\hline Negative & $503(87.9)$ & $14(2.4)$ & $517(90.4)$ & \multirow{3}{*}{0.001} & \multirow{3}{*}{0.311} & \multirow{3}{*}{0.176} & \multirow{3}{*}{0.446} \\
\hline Positive & $40(7.0)$ & $15(2.6)$ & $55(9.6)$ & & & & \\
\hline Total & $543(94.9)$ & $29(5.1)$ & $572(100.0)$ & & & & \\
\hline \multicolumn{8}{|l|}{ qPCR-serum } \\
\hline Negative & $574(93.8)$ & $29(4.7)$ & $603(98.5)$ & & & & \\
\hline Positive & $5(0.8)$ & $4(0.7)$ & $9(1.5)$ & $<0.001$ & 0.171 & 0.013 & 0.330 \\
\hline Total & $579(94.6)$ & $33(5.4)$ & $612(100.0)$ & & & & \\
\hline
\end{tabular}

or unisexual infections $[16,44,45]$. The possibility of crossreactivity with cercariae antigens from parasites that infect other animal species and cross-reactivity with other parasites must also be considered [28, 46-48].

The positivity rate of the COPT technique also differed significantly from the positivity rates of the parasitological techniques $(P<0.001)$. The level of concordance $(k=$ 0.224 ) for these techniques was higher than that observed for the other immunodiagnostic techniques (ELISA-IgG, ELISAIgM, and ITF-IgM).

This higher positivity rate observed for the COPT could be due to the fact that oviposition occurs with egg deposition in the deeper layers of the intestine, even when eggs are absent from the feces, mainly in chronic infections in patients over 40 years of age and in schistosomiasis infections with low parasite load $[49,50]$. 
TABLE 7: Description of the sensitivity, specificity, the positive likelihood ratio, the negative likelihood ratio, the positive predictive value, and the negative predictive value of all diagnostic techniques compared to the COPT technique in individuals from the city of Barra Mansa, RJ, 2011.

\begin{tabular}{|c|c|c|c|c|}
\hline \multirow{2}{*}{ Techniques } & \multirow{2}{*}{ Parameters } & \multirow{2}{*}{ Estimate } & \multicolumn{2}{|c|}{ IC (95\%) } \\
\hline & & & Lower & Higher \\
\hline \multirow{7}{*}{ KK-HH } & Sensitivity (\%) & 13.8 & 3.9 & 31.7 \\
\hline & Specificity (\%) & 99.8 & 99.0 & 100.0 \\
\hline & Likelihood ratio $(+)$ & 74.9 & 8.6 & 649.0 \\
\hline & Likelihood ratio (-) & 0.9 & 0.7 & 1.0 \\
\hline & Positive predictive value (PPV) (\%) & 80.0 & 28.4 & 99.5 \\
\hline & Negative predictive value (NPV) (\%) & 95.6 & 93.6 & 97.1 \\
\hline & Accuracy (\%) & 95.5 & 95.1 & 95.8 \\
\hline \multirow{7}{*}{ ELISA-IgG } & Sensitivity (\%) & 66.7 & 48.2 & 82.0 \\
\hline & Specificity (\%) & 91.5 & 89.0 & 93.7 \\
\hline & Likelihood ratio (+) & 7.9 & 5.5 & 11.3 \\
\hline & Likelihood ratio $(-)$ & 0.4 & 0.2 & 0.6 \\
\hline & Positive predictive value (PPV) (\%) & 31.0 & 20.5 & 43.1 \\
\hline & Negative predictive value (NPV) (\%) & 98.0 & 96.4 & 99.0 \\
\hline & Accuracy (\%) & 90.2 & 89.5 & 90.9 \\
\hline \multirow{7}{*}{ ELISA-IgM } & Sensitivity (\%) & 81.8 & 64.5 & 93.0 \\
\hline & Specificity (\%) & 82.0 & 78.7 & 85.1 \\
\hline & Likelihood ratio $(+)$ & 4.6 & 3.6 & 5.8 \\
\hline & Likelihood ratio $(-)$ & 0.2 & 0.1 & 0.4 \\
\hline & Positive predictive value (PPV) (\%) & 20.6 & 14.0 & 28.6 \\
\hline & Negative predictive value (NPV) (\%) & 98.8 & 97.3 & 99.5 \\
\hline & Accuracy (\%) & 82.0 & 80.9 & 83.2 \\
\hline \multirow{7}{*}{ IFT-IgM } & Sensitivity (\%) & 78.8 & 61.1 & 91.0 \\
\hline & Specificity (\%) & 87.7 & 84.8 & 90.3 \\
\hline & Likelihood ratio (+) & 6.4 & 4.9 & 8.5 \\
\hline & Likelihood ratio (-) & 0.2 & 0.1 & 0.5 \\
\hline & Positive predictive value (PPV) (\%) & 26.8 & 18.3 & 36.8 \\
\hline & Negative predictive value (NPV) (\%) & 98.6 & 97.2 & 99.5 \\
\hline & Accuracy (\%) & 87.3 & 86.4 & 88.1 \\
\hline \multirow{7}{*}{ qPCR-feces } & Sensitivity (\%) & 51.7 & 32.5 & 70.6 \\
\hline & Specificity (\%) & 92.6 & 90.1 & 94.7 \\
\hline & Likelihood ratio (+) & 7.0 & 4.4 & 11.1 \\
\hline & Likelihood ratio (-) & 0.5 & 0.3 & 0.8 \\
\hline & Positive predictive value (PPV) (\%) & 27.3 & 16.1 & 41.0 \\
\hline & Negative predictive value (NPV) (\%) & 97.3 & 95.5 & 98.5 \\
\hline & Accuracy (\%) & 90.6 & 89.9 & 91.3 \\
\hline \multirow{7}{*}{ qPCR-serum } & Sensitivity (\%) & 12.1 & 3.4 & 28.2 \\
\hline & Specificity (\%) & 99.1 & 98 & 99.7 \\
\hline & Likelihood ratio $(+)$ & 14.0 & 4.0 & 49.8 \\
\hline & Likelihood ratio (-) & 0.9 & 0.8 & 1.0 \\
\hline & Positive predictive value (PPV) (\%) & 44.4 & 13.7 & 78.8 \\
\hline & Negative predictive value (NPV) (\%) & 95.2 & 93.2 & 96.8 \\
\hline & Accuracy (\%) & 94.4 & 94 & 94.9 \\
\hline
\end{tabular}


The COPT positivity was lower than that for the ELISAIgG and ELISA-IgM and ITF-IgM tests, probably as a result of the different nature of the antigens. The COPT detects antibodies against excretion products and secretions of miracidia or antibodies against antigens present in the fluid surrounding S. mansoni eggs, whereas the ELISAIgG, ELISA-IgM, and ITF-IgM techniques detect antibodies against antigens in the internal coating of the digestive tube of adult worms $[32,50]$.

The appearance of the antibodies detected by the COPT is precocious and coincides with the beginning of the elimination of the eggs in the feces $[49,51,52]$. Thus, the antibodies detected by the COPT are only produced when worms of both sexes cause the infection; the ELISA-IgG, ELISA-IgM, and ITF-IgM techniques can also detect unisexual infections $[44,52,53]$.

To the best of our knowledge, this is the first time that qPCR-feces and qPCR-serum were used in a population study in low endemicity area for $S$. mansoni infection.

The qPCR-feces technique exhibited 12-fold higher positivity than the $\mathrm{KK}$ and $\mathrm{HH}$ techniques, at 9.8\% $(n=60)$ compared to $0.8 \%(n=5)$ for the parasitological techniques. The qPCR-feces positivity rate was only higher than the rates for the COPT (5.4\%) and the qPCR-serum (1.5\%) techniques; its results differed significantly from all techniques $(P<0.05)$ except the ELISA-IgG technique.

The positivity rate of the qPCR-serum technique was higher than those of the parasitological techniques but lower than those of the other techniques, including the qPCR-feces technique. A study by Pontes et al. [23] also indicated that the qPCR-serum technique has lesser sensitivity than the conventional PCR-feces technique for detecting S. mansoni infection. However, Wichmann et al. [54] and Zhou et al. [55] correlated the positivity in the acute phase of schistosomiasis infection with inflammatory alterations. The acute phase would cause increased circulation of schistosomiasis degradation products, both adult worms and eggs, thus increasing the quantity of circulating DNA. This phase would usually continue until the eighth week after infection, and these data would explain the higher rate of amplification using the qPCR-serum technique.

The median of the $\mathrm{Ct}$ values of the logarithmic curves for the qPCR-feces and serum techniques was 34.8 and 36.3 , respectively, indicating low amplification of the DNA template, found in egg fragments (0.02 eggs at a dilution of $1 / 10,000)$, based on the standardization of the technique. The low parasite load in S. mansoni infections observed in ALEs could explain this result [56].

Wichmann et al. [57] reported a higher positivity rate for the qPCR-serum technique in patients with acute schistosomiasis, using the presence of $S$. mansoni DNA in duplicate samples as a criterion for positivity, with a limit of $\mathrm{Ct}<45$.

In spite of the presence of factors that inhibit the qPCRfeces technique and the low parasite load in the sampled population, the qPCR-feces technique showed a 12-fold higher positivity rate $(60 / 610)$ than the $\mathrm{KK}$ and $\mathrm{HH}(5 / 610)$ techniques; the qPCR-serum technique presented a positivity (9/612) of, approximately, twofold higher than those of the parasitological techniques.
According to Cnops et al. [58], all PCR-based techniques for genomic DNA of S. mansoni were able to detect the DNA from all phases of the life cycle of this parasite: eggs containing miracidia, cercariae, schistosomulae, and adult worms. In summary, a positive PCR assay indicates the presence of the parasite but does not provide information regarding its life cycle phase or its viability, including the presence of mature, male, and female worms capable of egg deposition. This is likely to explain why we have not found a positive correlation between the Ct value and the number of eggs.

The technique developed by Kato and Miura [10], modified by Katz et al. [59], became the international reference technique for diagnosing schistosomiasis infection [60]. However, a decline in the sensitivity of this technique was observed in individuals with low parasite load infections residing in ALEs, following specific treatment, which compromises the evaluation of new techniques for diagnosing infection by $S$. mansoni, when it is used as a reference $[61,62]$.

Various studies have been performed to identify alternative methods of diagnosis applicable on a large scale that could be used to aid the programs for epidemiological vigilance in areas where, despite control actions, new cases of confirmed autochthony still occur [63].

Immunodiagnostic techniques are still used in schistosomiasis control programs in countries such as China and Venezuela [43, 50, 64, 65]. In Brazil, various techniques have been tested in regions considered to have low endemicity, such as in the states of São Paulo and Rio de Janeiro [28, 40, 48, 66-68].

The COPT is considered by some researchers to be the gold-standard technique for diagnosing schistosomiasis in ALEs $[69,70]$.

Taking into account the possibility of employing parasitological and immunological techniques for diagnosing schistosomiasis infection in ALEs, Alarcón de Noya et al. [50] proposed three laboratory criteria for case definition in these areas:

(I) individuals eliminating S. mansoni eggs in feces. In this group, COPT and serological positivity reactions are common;

(II) individuals without $S$. mansoni eggs in their feces, with positive COPT who have not received specific treatment in the previous 12 months. Usually, this group shows positivity for one and/or two serological techniques;

(III) individuals without S. mansoni eggs in their feces with negative COPT who have not received specific treatment in the previous 12 months but who have shown positivity for two serological techniques.

Use of criteria (I) and (II) presented above would yield 34 positive cases in our study population, and the prevalence would be, approximately, 5.6\% (34/612) greater than the prevalence detected by the parasitological techniques $0.8 \%$ (5/612) prevalence detected by the parasitological techniques used in the program for schistosomiasis vigilance.

As we verified in this study, various techniques could be used for diagnosis of schistosomiasis; however all present 
problems of sensitivity or specificity. Thus, we could not identify in this study the ideal technique that combines high rates of sensitivity and specificity and low cost and easy applicability, even in the field, probably due to the low prevalence of infection (approximately 1\%) in the area studied. All assays employed showed low sensitivity and specificity when applied to the study population. Low parasite load, very recent infections, and the low number of positive parasitological exams may explain this.

One limitation of this study is the collection of a single fecal sample per individual as recommended by the guidelines of the National Program for Schistosomiasis, since the sensitivity of the KK test could have been improved by testing samples collected on two or three successive days to compensate for daily variation in egg production in an infected individual.

The present study indicates that the use of combined tools can improve the diagnosis of low parasite load $S$. mansoni infections, in both clinical and epidemiological studies. The benefits of parasitological techniques for the control of $S$. mansoni are widely recognized, particularly the KK technique. We consider the presence of ALEs to be an indicator of the positive outcome of schistosomiasis control programs worldwide. However, in order to eliminate the risk of schistosomiasis in populations of low endemicity areas, the pursuit of novel techniques must be considered. Potentially effective methods may include novel immunodiagnostic techniques, molecular biology tools, and parasitological techniques, such as saline gradient, and magnetic bead-based isolation of eggs [26, 37, 71-75]. The development of these tools and the subsequent elimination of schistosomiasis will be a great challenge that will require the combined efforts of governments, health professionals, and researchers.

To advance this agenda, we suggest a change to the third criterion proposed by Alarcón de Noya et al. [50], considering cases of schistosomiasis in which individuals present positive qPCR-serum and/or qPCR-feces results. We withdrew the criterion regarding positivity in two serological techniques and negative results in the parasitological and the COPT techniques (Table 8).

With regard to field activities, we propose serological and parasitological survey of ALEs. We recommend the use of the ELISA-IgM and ELISA-IgG techniques for an initial triage of the target population, due to their greater sensitivity, to the possibility of automation, and to their ability to provide quantitative results. We suggest the use of the $\mathrm{KK}$ and $\mathrm{HH}$ parasitological techniques for evaluating the intensity of $S$. mansoni infections and identifying the presence of other parasitic infections, respectively.

Following the triage, we recommend that actions be determined according to laboratory classification criteria. Thus, individuals classified under criteria (I), (II), and (III) would be referred for clinical evaluation, specific chemotherapy, and health education. For individuals with positive results for one and/or two serological techniques (ELISAIgG or ELISA-IgM), we propose performing the COPT. For the patients who present a positive COPT, we recommend a clinical evaluation, treatment, and health education. If the result of the COPT is negative, we recommend performing
TABLE 8: Proposal for laboratory criteria for defining cases of schistosomiasis in ALEs.

\begin{tabular}{|c|c|c|}
\hline Criterion I & Criterion II & Criterion III \\
\hline $\begin{array}{l}\text { Individuals } \\
\text { eliminating } S \text {. } \\
\text { mansoni eggs in } \\
\text { feces }\end{array}$ & Positive COPT & $\begin{array}{l}\text { Individuals with no } S \text {. } \\
\text { mansoni eggs in feces }\end{array}$ \\
\hline $\begin{array}{l}\text { With/without } \\
\text { positive COPT }\end{array}$ & $\begin{array}{l}\text { Individuals with no } \\
S \text {. mansoni eggs in } \\
\text { feces }\end{array}$ & Negative COPT \\
\hline \multirow[t]{2}{*}{$\begin{array}{l}\text { With/without } \\
\text { positive } \\
\text { ELISA-IgM and/or } \\
\text { ELISA-IgG } \\
\text { techniques }\end{array}$} & $\begin{array}{l}\text { Without specific } \\
\text { treatment in the last } \\
12 \text { months }\end{array}$ & \\
\hline & $\begin{array}{l}\text { With/without } \\
\text { positive ELISA-IgM } \\
\text { and/or ELISA-IgG } \\
\text { techniques }\end{array}$ & $\begin{array}{l}\text { Positive qPCR-serum } \\
\text { and/or positive } \\
\text { qPCR-feces }\end{array}$ \\
\hline
\end{tabular}

qPCR-feces and qPCR-serum; if any of these molecular techniques yield a positive result, we suggest clinical evaluation, specific treatment, and health education (Figure 5).

We propose the combination of the ELISA-IgM and IgG techniques in the triage phase due to the possibility of automation, and to their higher levels of sensitivity, thus enabling the identification of a greater number of cases. In addition, the ELISA-IgM technique is more sensitive and the ELISA-IgG technique is more specific; hence, their combination will improve diagnosis.

According to our proposal, positivity of one or two immunological techniques indicates the need for confirmation by the COPT, which, despite being more difficult to perform, can identify active infections, or by the molecular reactions, which can identify the presence of the parasite at any stage of infection.

The possibility of the use of rapid tests with recombinant antigens [76] or with Circulating Anodic Antigen (CAA) in urine, feces, or serum [77-80] might be an interesting alternative for field works in places where health workers do not have the proper training and equipment to perform sophisticated serological assays.

However, continued use of the parasitological techniques will be important, in particular the $\mathrm{HH}$ technique, as it permits the evaluation of the parasite load in positive cases and allows observation of different levels of prevalence as well. Besides the evaluation and treatment, the infection risk factors must be taken into account.

We believe that maintaining this level of surveillance in ALEs will present a great challenge and will require evaluation of costs, interactions with other studies, and finally a broad discussion involving the various actors in the context of public health, research, and society.

In Brazil, recent epidemiological data on S. mansoni point to an increase in ALEs, and the current proposal aims to interrupt the transmission of this helminth (Ordinance number 2,556 of 28 October 2011). In this context, diagnosis of $S$. mansoni becomes a strategic hurdle we must overcome 


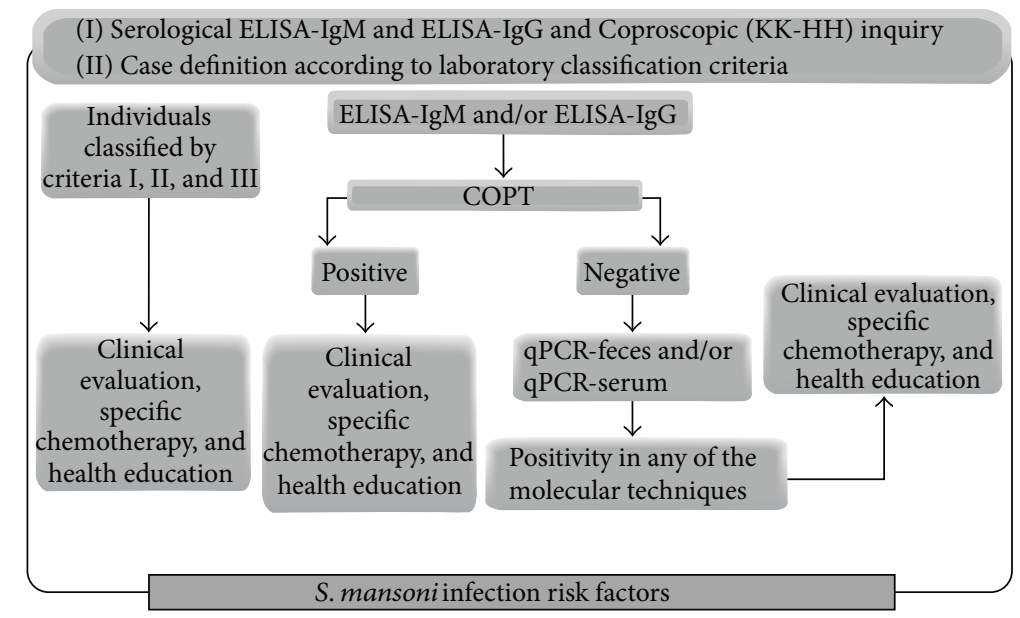

FIGURE 5: Proposal for epidemiological vigilance in ALEs.

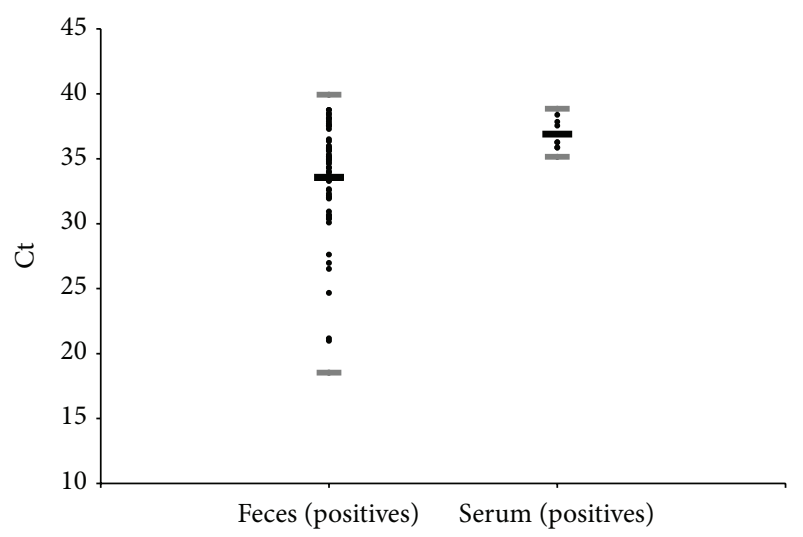

FIgURE 6: Description of the threshold cycle (Ct) for the results from the positive and qPCR in serum and feces samples from the individuals sampled from the city of Barra Mansa/RJ, 2011.

in order to reach the desired result indicators in the process of eliminating this parasitic infection. In addition, the development of new diagnostic laboratory techniques for detecting low parasite load infections represents an important strategy to overcome this need, in clinical contexts as well as in public health.

\section{Conflict of Interests}

The authors declare that they have no competing interests.

\section{Authors' Contribution}

Maria Cristina Carvalho do Espírito-Santo, Mónica Viviana Alvarado-Mora, Pedro Luiz Silva Pinto, Expedito José de Albuquerque Luna, and Ronaldo Cesar Borges Gryschek conceived and designed the experiments. Maria Cristina Carvalho do Espírito-Santo, Mónica Viviana Alvarado-Mora, Emmanuel Dias-Neto, Pedro Luiz Silva Pinto, Maria Carmen Arroyo Sanchez, João Renato Rebello Pinho, Vera
Lúcia Pagliusi Castilho, and Elenice Messias do Nascimento Gonçalves performed the experiments. Maria Cristina Carvalho do Espírito-Santo, João Renato Rebello Pinho, Flair José Carrilho, Expedito José de Albuquerque Luna, Emmanuel Dias-Neto, and Ronaldo Cesar Borges Gryschek contributed with reagents/material/analysis tools. Maria Cristina Carvalho do Espírito-Santo, Mónica Viviana Alvarado-Mora, Expedito José de Albuquerque Luna, Maria Carmen Arroyo Sanchez, Pedro Luiz Silva Pinto, João Renato Rebello Pinho, Emmanuel Dias-Neto, and Ronaldo Cesar Borges Gryschek wrote/edited the paper. All authors read and approved the final paper.

\section{Acknowledgments}

This study was supported by the São Paulo Research Foundation (Grants 07/53457-7, 08/50461-6, and 10/52615-0). The authors would also like to thank Ms. Maria Cristina Conceição de Mello (LIM-06-FMUSP) for her excellent technical assistance concerning the maintenance of the $S$. mansoni biological cycle. Emmanuel Dias-Neto and João Renato Rebello Pinho are research fellows of the Conselho Nacional de Desenvolvimento Científico e Tecnológico (CNPq). Finally, they would like to thank Dr. Wilton Neri and staff of the Municipal Health Department of Barra Mansa, Rio de Janeiro, Brazil.

\section{References}

[1] L. Chitsulo, D. Engels, A. Montresor, and L. Savioli, "The global status of schistosomiasis and its control," Acta Tropica, vol. 77, no. 1, pp. 41-51, 2000.

[2] WHO, Schistosomiasis. Fact Sheet no. 115, World Health Organization, Geneva, Switzerland, 2014, http://www.who.int/mediacentre/factsheets/fs115/en/.

[3] Ministry of Health, Department of Health Surveillance, Information System of Schistosomiasis Control Program, and Diseases Information System, Confirmed Cases of Schistosomiasis. Brazil, Major Regions and Federative Units. From 1995 to 2011, 
Ministry of Health, Department of Health Surveillance, Information System of Schistosomiasis Control Program, Diseases Information System, Brasília, Brazil, 2012.

[4] N. R. Bergquist, "Schistosomiasis: from risk assessment to control," Trends in Parasitology, vol. 18, no. 7, pp. 309-314, 2002.

[5] L. C. Pordeus, L. R. Aguiar, L. R. M. Quinino, and C. S. Barbosa, "A ocorrência das formas aguda e crônica da esquistossomose mansônica no Brasil no período de 1997 a 2006: uma revisão de literatura," Epidemiologia e Serviços de Saúde, vol. 17, no. 3, pp. 163-175, 2008.

[6] WHO, "Prevention and control of schistosomiasis and soiltransmitted helminthiasis: report of a WHO expert committee on the Control of Schistosomiasis," Technical Report Series 912, WHO, Geneva, Switzerland, 2002.

[7] Ministry of Health. Health Surveillance Secretariat. Department of Analysis of Health Situations, Mortality Information System. Deaths from Schistosomiasis, Major Regions and Federative Units, 1990 to 2011, Ministry of Health, Brasília, Brazil, 2012.

[8] State Department of Health and Civil Defense and Government of the State of Rio de Janeiro, Health Information Booklet of the State of Rio de Janeiro, Government of the State of Rio de Janeiro, Rio de Janeiro, Brazil, 2009.

[9] Municipal Health Secretariat and Epidemiology Coordination Office, "Documents taken from SINANNET/07-05-2008," Barra Mansa, Rio de Janeiro, Brazil, 2008.

[10] K. Kato and M. Miura, "Comparative examinations," Japanese Journal of Parasitology, vol. 3, p. 35, 1954.

[11] L. K. Martin and P. C. Beaver, "Evaluation of Kato thick-smear technique for quantitative diagnosis of helminth infections," The American Journal of Tropical Medicine and Hygiene, vol. 17, no. 3, pp. 382-391, 1968.

[12] W. A. Hoffman, J. A. Pons, and J. L. Janer, "The sedimentationconcentration method in schistosomiasis mansoni," The Puerto Rico Journal of Public Health and Tropical Medicine, vol. 9, pp. 283-291, 1934.

[13] E. Ruiz-Tiben, G. V. Hillyer, W. B. Knight, I. Gómez de Rios, and J. P. Woodall, "Intensity of infection with Schistosoma mansoni: its relationship to the sensitivity and specificity of serologic tests," American Journal of Tropical Medicine and Hygiene, vol. 28, no. 2, pp. 230-236, 1979.

[14] A. Sleigh, R. Hoff, K. Mott et al., "Comparison of filtration staining (Bell) and thick smear (Kato) for the detection and quantitation of Schistosoma mansoni eggs in faeces," Transactions of the Royal Society of Tropical Medicine and Hygiene, vol. 76, no. 3, pp. 403-406, 1982.

[15] M. L. Barreto, D. H. Smith, and A. C. Sleigh, "Implications of faecal egg count variation when using the Kato-Katz method to assess Schistosoma mansoni infections," Transactions of the Royal Society of Tropical Medicine and Hygiene, vol. 84, no. 4, pp. 554-555, 1990.

[16] S. J. de Vlas and B. Gryseels, "Underestimation of Schistosoma mansoni prevalences," Parasitology Today, vol. 8, no. 8, pp. 274277, 1992.

[17] B. Gryseels and S. J. de Vlas, "Worm burdens in schistosome infections," Parasitology Today, vol. 12, no. 3, pp. 115-119, 1996.

[18] A. Ebrahim, H. El-Morshedy, E. Omer, S. El-Daly, and R. Barakat, "Evaluation of the Kato-Katz thick smear and formol ether sedimentation techniques for quantitative diagnosis of Schistosoma mansoni infection," The American Journal of Tropical Medicine and Hygiene, vol. 57, no. 6, pp. 706-708, 1997.
[19] G. V. Hillyer, E. Ruiz Tiben, W. B. Knight, I. Gómez de Rios, and R. P. Pelley, "Immunodiagnosis of infection with Schistosoma mansoni: comparison of ELISA, radioimmunoassay, and precipitation tests performed with antigens from eggs," The American Journal of Tropical Medicine and Hygiene, vol. 28, no. 4, pp. 661-669, 1979.

[20] Y. Zhu, W. He, Y. Liang et al., "Development of a rapid, simple dipstick dye immunoassay for schistosomiasis diagnosis," Journal of Immunological Methods, vol. 266, no. 1-2, pp. 1-5, 2002.

[21] D. G. Altman, Practical Statistics for Medical Research, Chapman \& Hall, London, UK, 1991.

[22] Her Majesty's Stationery Office (HSMO) and Office of Public Sector Information (OPSI), Geneva Conventions (Amendment) Act 1995 (c. 27), Her Majesty's Stationery Office (HSMO), Office of Public Sector Information (OPSI), 1995.

[23] L. A. Pontes, M. C. Oliveira, N. Katz, E. Dias-Neto, and A. Rabello, "Comparison of a polymerase chain reaction and the Kato-Katz technique for diagnosing infection with Schistosoma mansoni," The American Journal of Tropical Medicine and Hygiene, vol. 68, no. 6, pp. 652-656, 2003.

[24] O. H. Lowry, N. J. Rosebrough, A. L. Farr, and R. J. Randall, "Protein measurement with the Folin phenol reagent," The Journal of Biological Chemistry, vol. 193, no. 1, pp. 265-275, 1951.

[25] G. L. Peterson, "Review of the Folin phenol protein quantitation method of Lowry, Rosebrough, Farr and Randall," Analytical Biochemistry, vol. 100, no. 2, pp. 201-220, 1979.

[26] M. C. Espirito-Santo, M. C. Sanchez, A. R. Sanchez et al., "Evaluation of the sensitivity of IgG and IgM ELISA in detecting Schistosoma mansoni infections in a low endemicity setting," European Journal of Clinical Microbiology \& Infectious Diseases, vol. 33, no. 12, pp. 2275-2284, 2014.

[27] A. M. Deelder, H. T. M. Klappe, G. J. M. J. van den Aardweg, and E. H. E. M. van Meerbeke, "Schistosoma mansoni: demonstration to two circulating antigens in infected hamsters," Experimental Parasitology, vol. 40, no. 2, pp. 189-197, 1976.

[28] E. J. de Oliveira, H. Y. Kanamura, and D. M. Correia Lima, "Efficacy of an enzyme-linked immunosorbent assay as a diagnostic tool for schistosomiasis mansoni in individuals with low worm burden," Memorias do Instituto Oswaldo Cruz, vol. 100, no. 4, pp. 421-425, 2005.

[29] R. M. Silva, M. I. P. G. Silva, S. A. G. Vellosa, E. T. Garcia, and H. Y. Kanamura, "Pesquisa de anticorpos IgM contra tubo digestivo do verme para prognóstico da esquistossomose mansônica," Revista Brasileira de Patologia Clínica, vol. 28, pp. 39-42, 1992.

[30] T. E. Nash, "Localization of the circulating antigen within the gut of Schistosoma mansoni," American Journal of Tropical Medicine and Hygiene, vol. 23, no. 6, pp. 1085-1087, 1974.

[31] T. E. Nash, "Antibody response to a polysaccharide antigen present in the schistosome gut. I. Sensitivity and specificity," The American Journal of Tropical Medicine and Hygiene, vol. 27, no. 5, pp. 939-943, 1978.

[32] J. OLIVER-GONZALEZ, "Anti-egg precipitins in the serum of humans infected with Schistosoma mansoni.," The Journal of infectious diseases, vol. 95, no. 1, pp. 86-91, 1954.

[33] M. H. Dresden and D. C. Payne, "A sieving method for the collection of schistosome eggs from mouse intestines," Journal of Parasitology, vol. 67, no. 3, pp. 450-452, 1981.

[34] P. L. S. Pinto, L. D. Floriano, S. C. Ferreira, L. M. Suto, and S. A. G. Vellosa, "Purificação de ovos de Schistosoma mansoni a partir de vísceras de hamsters (Crycetus auratus) 
experimentalmente infectados," in XIV Congresso da Sociedade Brasileira de Parasitologia, vol. 23, p. 264, Revista de Patologia Tropical, Goiânia, Brazil, 1995.

[35] O. Noya, B. Alarcón de Noya, S. Losada et al., "Laboratory diagnosis of schistosomiasis in areas of low transmission: a review of a line of research," Memorias do Instituto Oswaldo Cruz, vol. 97, no. 1, pp. 167-169, 2002.

[36] P. Chomczynski and N. Sacchi, "Single-step method of RNA isolation by acid guanidinium thiocyanate-phenol-chloroform extraction," Analytical Biochemistry, vol. 162, no. 1, pp. 156-159, 1987.

[37] M. C. C. do Espírito-Santo, M. V. Alvarado-Mora, P. L. S. Pinto, F. J. Carrilho, J. R. R. Pinho, and R. C. B. Gryschek, "Two sequential PCR amplifications for detection of Schistosoma mansoni in stool samples with low parasite load," Revista do Instituto de Medicina Tropical de Sao Paulo, vol. 54, no. 5, pp. 245-248, 2012.

[38] M. C. Espírito-Santo, M. V. Alvarado-Mora, E. Dias-Neto et al., "Evaluation of real-time PCR assay to detect Schistosoma mansoni infections in a low endemic setting," BMC Infectious Diseases, vol. 14, no. 1, article 558, 2014.

[39] J. Hamburger, T. Turetski, I. Kapeller, and R. Deresiewicz, "Highly repeated short DNA sequences in the genome of Schistosoma mansoni recognized by a species-specific probe," Molecular and Biochemical Parasitology, vol. 44, no. 1, pp. 7380, 1991.

[40] H. M. Santana Teles, M. E. De Carvalho, C. Santos Ferreira, F. Zacharias, V. R. De Lima, and M. L. Condino Fadel, "Schistosomiasis mansoni in Bananal (State of São Paulo, Brazil). I. Efficiency of diagnostic and treatment procedures," Memorias do Instituto Oswaldo Cruz, vol. 97, no. 1, pp. 181-186, 2002.

[41] B. A. de Noya, C. Colmenares, H. Lanz, M. A. Caracciolo, S. Losada, and O. Noya, "Schistosoma mansoni: immunodiagnosis is improved by sodium metaperiodate which reduces crossreactivity due to glycosylated epitopes of soluble egg antigen," Experimental Parasitology, vol. 95, no. 2, pp. 106-112, 2000.

[42] M. M. L. Gonçalves, M. G. M. Barreto, R. H. S. Peralta et al., "Immunoassays as an auxiliary tool for the serodiagnosis of Schistosoma mansoni infection in individuals with low intensity of egg elimination," Acta Tropica, vol. 100, no. 1-2, pp. 24-30, 2006.

[43] W. Wang, Y. Li, H. Li et al., "Immunodiagnostic efficacy of detection of Schistosoma japonicum human infections in China: a meta analysis," Asian Pacific Journal of Tropical Medicine, vol. 5, no. 1, pp. 15-23, 2012.

[44] A. W. Cheever, "A quantitative post-mortem study of Schistosomiasis mansoni in man," American Journal of Tropical Medicine and Hygiene, vol. 17, no. 1, pp. 38-64, 1968.

[45] D. Engels, E. Sinzinkayo, S. J. de Vlas, and B. Gryseels, "Intraspecimen fecal egg count variation in Schistosoma mansoni infection," The American Journal of Tropical Medicine and Hygiene, vol. 57, no. 5, pp. 571-577, 1997.

[46] J. M. Ruiz, "Cercaria species indexes of Schistosoma mansoni verified in Neves and Mariana, State of Minas Gerais," Memórias do Instituto Butantan, vol. 24, no. 1, pp. 63-65, 1952.

[47] R. Correa-Oliveira, L. M. S. Dusse, I. R. C. Viana, D. G. Colley, O. S. Carvalho, and G. Gazzinelli, "Human antibody responses against schistosomal antigens. I. Antibodies from patients with Ancylostoma, Ascaris lumbricoides or Schistosoma mansoni infections react with schistosome antigens," The American Journal of Tropical Medicine and Hygiene, vol. 38, no. 2, pp. 348355, 1988.
[48] H. Y. Kanamura, L. C. D. S. Dias, R. M. Da Silva et al., "A comparative epidemiologic study of specific antibodies (IgM and $\operatorname{Ig} \mathrm{A}$ ) and parasitological findings in an endemic area of low transmission of Schistosoma mansoni," Revista do Instituto de Medicina Tropical de Sao Paulo, vol. 40, no. 2, pp. 85-91, 1998.

[49] K. Kloetzel, "A reação de precipitação periovular na esquistossomose. II. Correlação aos dados clínicos," Revista do Instituto de Medicina Tropical de São Paulo, vol. 1, pp. 129-137, 1959.

[50] B. Alarcón de Noya, R. Ruiz, S. Losada et al., "Detection of schistosomiasis cases in low-transmission areas based on coprologic and serologic criteria. The Venezuelan experience," Acta Tropica, vol. 103, no. 1, pp. 41-49, 2007.

[51] C. M. Coker and J. Oliver-Gonzalez, "Experiments on antischistosome circumoval precipitating antibody in mice," The American Journal of Tropical Medicine and Hygiene, vol. 7, p. 390, 1957.

[52] L. B. Senterfit, "Immobilization of the miracidia of Schistosoma mansoni by immune sera: II. The occurrence of the antibody during the course of schistosomiasis," American Journal of Epidemiology, vol. 68, no. 2, pp. 148-155, 1958.

[53] J. Oliver-Gonzalez, P. M. Bauman, and A. S. Benenson, "Immunological aspects of infections with Schistosoma mansoni," The American Journal of Tropical Medicine and Hygiene, vol. 4, no. 3, pp. 443-452, 1955.

[54] D. Wichmann, M. Panning, T. Quack et al., "Diagnosing schistosomiasis by detection of cell-free parasite DNA in human plasma," PLoS Neglected Tropical Diseases, vol. 3, no. 4, article e422, 2009.

[55] L. Zhou, J. Tang, Y. Zhao et al., "A highly sensitive TaqMan realtime PCR assay for early detection of Schistosoma species," Acta Tropica, vol. 120, no. 1-2, pp. 88-94, 2011.

[56] R. J. Ten Hove, J. J. Verweij, K. Vereecken, K. Polman, L. Dieye, and L. van Lieshout, "Multiplex real-time PCR for the detection and quantification of Schistosoma mansoni and S. haematobium infection in stool samples collected in northern Senegal," Transactions of the Royal Society of Tropical Medicine and Hygiene, vol. 102, no. 2, pp. 179-185, 2008.

[57] D. Wichmann, S. Poppert, H. Von Thien et al., "Prospective European-wide multicentre study on a blood based real-time PCR for the diagnosis of acute schistosomiasis," BMC Infectious Diseases, vol. 13, no. 1, article 55, 2013.

[58] L. Cnops, E. Tannich, K. Polman, J. Clerinx, and M. Van Esbroeck, "Schistosoma real-time PCR as diagnostic tool for international travellers and migrants," Tropical Medicine and International Health, vol. 17, no. 10, pp. 1208-1216, 2012.

[59] N. Katz, A. Chaves, and J. Pellegrino, "A simple device for quantitative stool thick-smear technique in Schistosomiasis mansoni," Revista do Instituto de Medicina Tropical de Sao Paulo, vol. 14, no. 6, pp. 397-400, 1972.

[60] WHO Expert Committee on the Control of Schistosomiasis, "Prevention and control of schistosomiasis and soiltransmitted helminthiasis: report of a WHO expert committee," WHO Technical Report Series 912, World Health Organization, Geneva, Switzerland, 2002, http://whqlibdoc.who.int/trs/ WHO_TRS_912.pdf.

[61] M. J. Enk, A. C. L. Lima, S. C. Drummond, V. T. Schall, and P. M. Z. Coelho, "The effect of the number of stool samples on the observed prevalence and the infection intensity with Schistosoma mansoni among a population in an area of low transmission," Acta Tropica, vol. 108, no. 2-3, pp. 222-228, 2008.

[62] Y.-Y. Zhang, J.-P. Luo, Y.-M. Liu et al., "Evaluation of Kato-Katz examination method in three areas with low-level endemicity 
of schistosomiasis japonica in China: a Bayesian modeling approach," Acta Tropica, vol. 112, no. 1, pp. 16-22, 2009.

[63] WHO, World Health Organization Elimination of Schistosomiasis from Low-Transmission Areas. Report of a WHO Informal Consultation. Salvador, Bahia, Brazil. 18-19 Aug 2008, WHO, Geneva, Switzerland, 2009.

[64] Y.-C. Zhu, "Immunodiagnosis and its role in schistosomiasis control in China: a review," Acta Tropica, vol. 96, no. 2-3, pp. 130-136, 2005.

[65] B. A. de Noya, R. Ruiz-Guevara, C. Colmenares, S. Losada, and O. Noya, "Low transmission areas of schistosomiasis in Venezuela: consequences on the diagnosis, treatment, and control," Memorias do Instituto Oswaldo Cruz, vol. 101, no. 1, pp. 29-35, 2006.

[66] H. Y. Kanamura, L. C. S. Dias, C. M. Glasser et al., "Detection of IgM antibodies to Schistosoma mansoni gut-associated antigens for the study of the dynamics of schistosomiasis transmission in an endemic area with low worm burden," Revista do Instituto de Medicina Tropical de São Paulo, vol. 40, no. 4, pp. 225-231, 1998.

[67] F. Zacharias, M. E. De Carvalho, C. Gargioni, H. M. Santana Teles, C. S. Ferreira, and V. R. De Lima, "Schistosomiasis mansoni in Bananal (State of São Paulo, Brazil). III. Seroepidemiological studies in the Palha district," Memorias do Instituto Oswaldo Cruz, vol. 97, no. 1, pp. 19-22, 2002.

[68] L. M. A. Oliveira, H. L. C. Santos, M. M. L. Gonçalves, M. G. M. Barreto, and J. M. Peralta, "Evaluation of polymerase chain reaction as an additional tool for the diagnosis of low-intensity Schistosoma mansoni infection," Diagnostic Microbiology and Infectious Disease, vol. 68, no. 4, pp. 416-421, 2010.

[69] L. Spencer, B. Alarcón de Noya, O. Noya, and G. Masroua, "Comparative analysis between the circumoval precipitin test and ELISA with raw antigens for the diagnosis of schistosomiasis in Venezuela," GEN, vol. 45, no. 2, pp. 77-83, 1991.

[70] B. A. Alarcón de Noya, O. Noya, C. Balzan, and I. M. Cesari, "New approaches for the control and eradication of schistosomiasis in Venezuela," Memorias do Instituto Oswaldo Cruz, vol. 87, pp. 227-231, 1992.

[71] T. R. Carneiro, M. C. Cunha Pinheiro, S. M. de Oliveira, A. L. de Paula Hanemann, J. A. Nogueira Queiroz, and F. S. Moraes Bezerra, "Increased detection of schistosomiasis with Kato-Katz and SWAP- IgG-ELISA in a Northeastern Brazil low-intensity transmission area," Revista da Sociedade Brasileira de Medicina Tropical, vol. 45, no. 4, pp. 510-513, 2012.

[72] L. I. Gomes, L. H. D. S. Marques, M. J. Enk, M. C. de Oliveira, P. M. Z. Coelho, and A. Rabello, "Development and evaluation of a sensitive PCR-ELISA system for detection of Schistosoma infection in feces," PLoS Neglected Tropical Diseases, vol. 4, no. 4, article e664, 2010.

[73] L. A. Pontes, E. Dias-Neto, and A. Rabello, "Detection by polymerase chain reaction of Schistosoma mansoni DNA in human serum and feces," The American Journal of Tropical Medicine and Hygiene, vol. 66, no. 2, pp. 157-162, 2002.

[74] P. M. Z. Coelho, A. D. Jurberg, Á. A. Oliveira, and N. Katz, "Use of a saline gradient for the diagnosis of schistosomiasis," Memorias do Instituto Oswaldo Cruz, vol. 104, no. 5, pp. 720723, 2009.

[75] C. Fagundes Teixeira, E. Neuhauss, R. Ben, J. Romanzini, and C. Graeff-Teixeira, "Detection of Schistosoma mansoni eggs in feces through their interaction with paramagnetic beads in a magnetic field," PLoS Neglected Tropical Diseases, vol. 1, no. 2, article e73, 2007.
[76] Z. Demerdash, S. Mohamed, M. Hendawy et al., "Monoclonal antibody-based dipstick assay: a reliable field applicable technique for diagnosis of Schistosoma mansoni infection using human serum and urine samples," Korean Journal of Parasitology, vol. 51, no. 1, pp. 93-98, 2013.

[77] A. M. Deelder, N. de Jonge, Y. E. Fillié et al., "Quantitative determination of circulating antigens in human schistosomiasis mansoni using an indirect hemagglutination assay," The American Journal of Tropical Medicine and Hygiene, vol. 40, no. 1, pp. 50-54, 1989.

[78] L. van Lieshout, U. Gangaram Panday, N. de Jonge et al., "Immunodiagnosis of schistosomiasis mansoni in a low endemic area in Surinam by determination of the circulating antigens CAA and CCA," Acta Tropica, vol. 59, no. 1, pp. 19-29, 1995.

[79] K. Polman, F. F. Stelma, B. Gryseels et al., "Epidemiologic application of circulating antigen detection in a recent Schistosoma mansoni focus in Northern Senegal," The American Journal of Tropical Medicine and Hygiene, vol. 53, no. 2, pp. 152-157, 1995.

[80] L. Van Lieshout, A. M. Polderman, and A. M. Deelder, "Immunodiagnosis of schistosomiasis by determination of the circulating antigens CAA and CCA, in particular in individuals with recent or light infections," Acta Tropica, vol. 77, no. 1, pp. 69-80, 2000. 

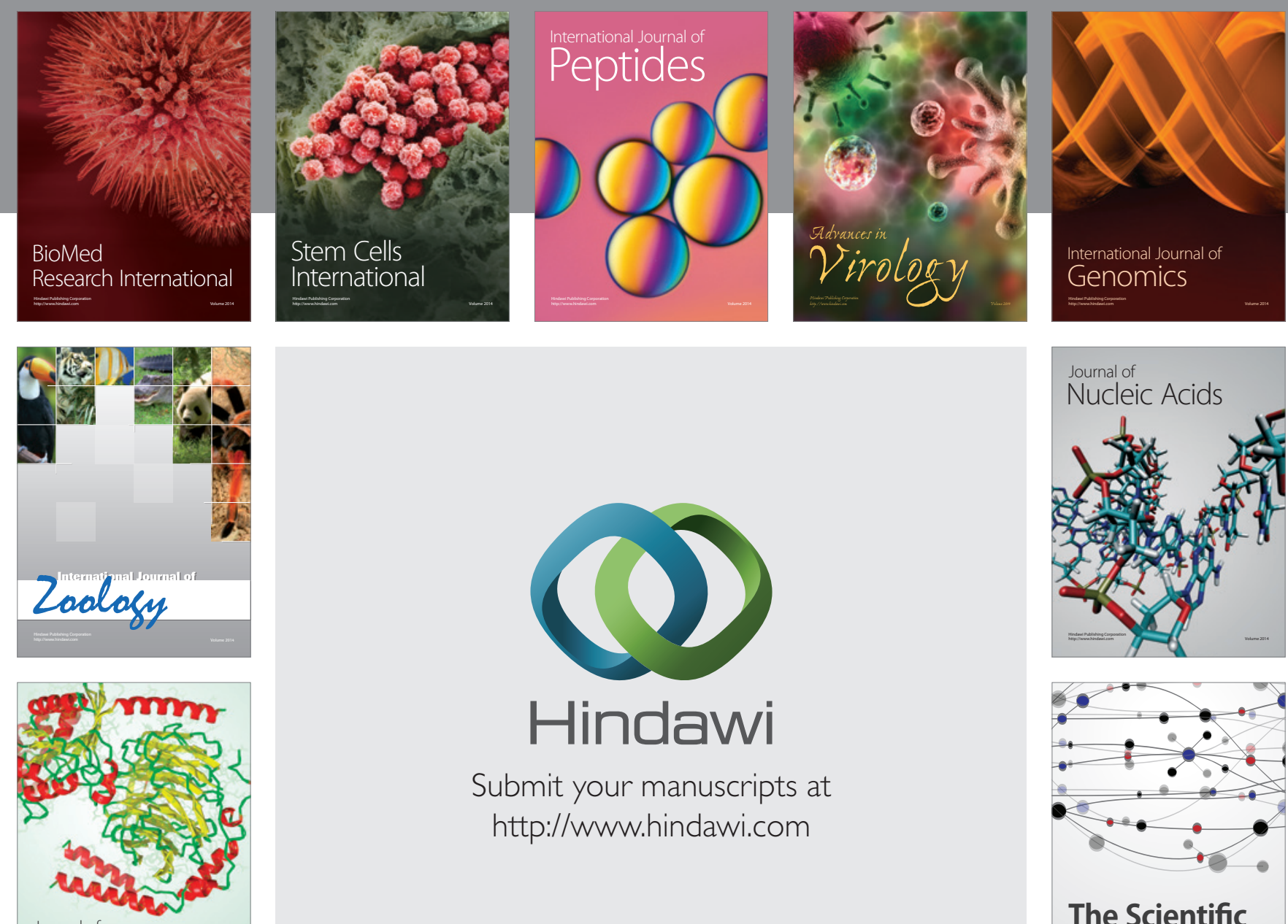

Submit your manuscripts at

http://www.hindawi.com

Journal of
Signal Transduction
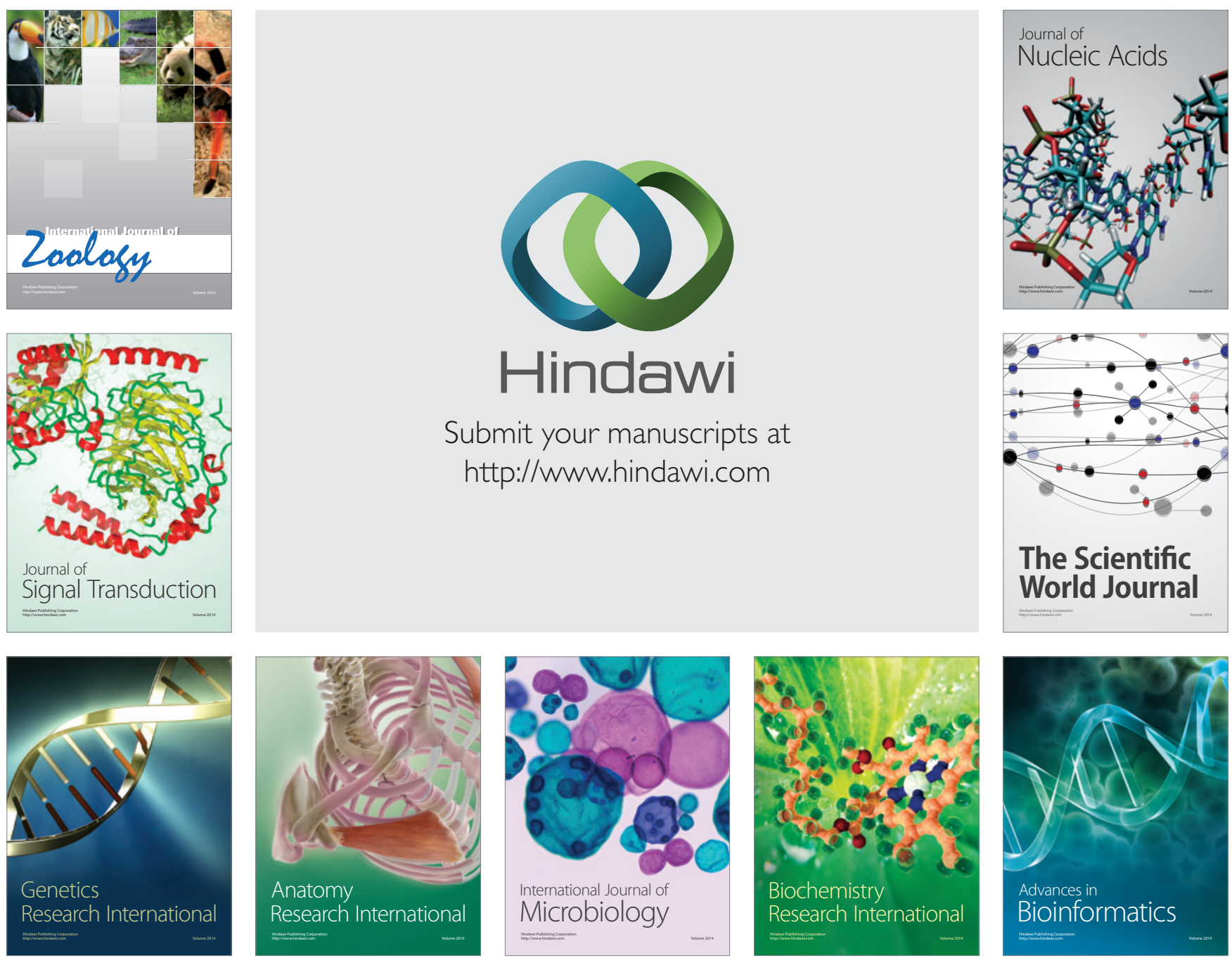

The Scientific World Journal
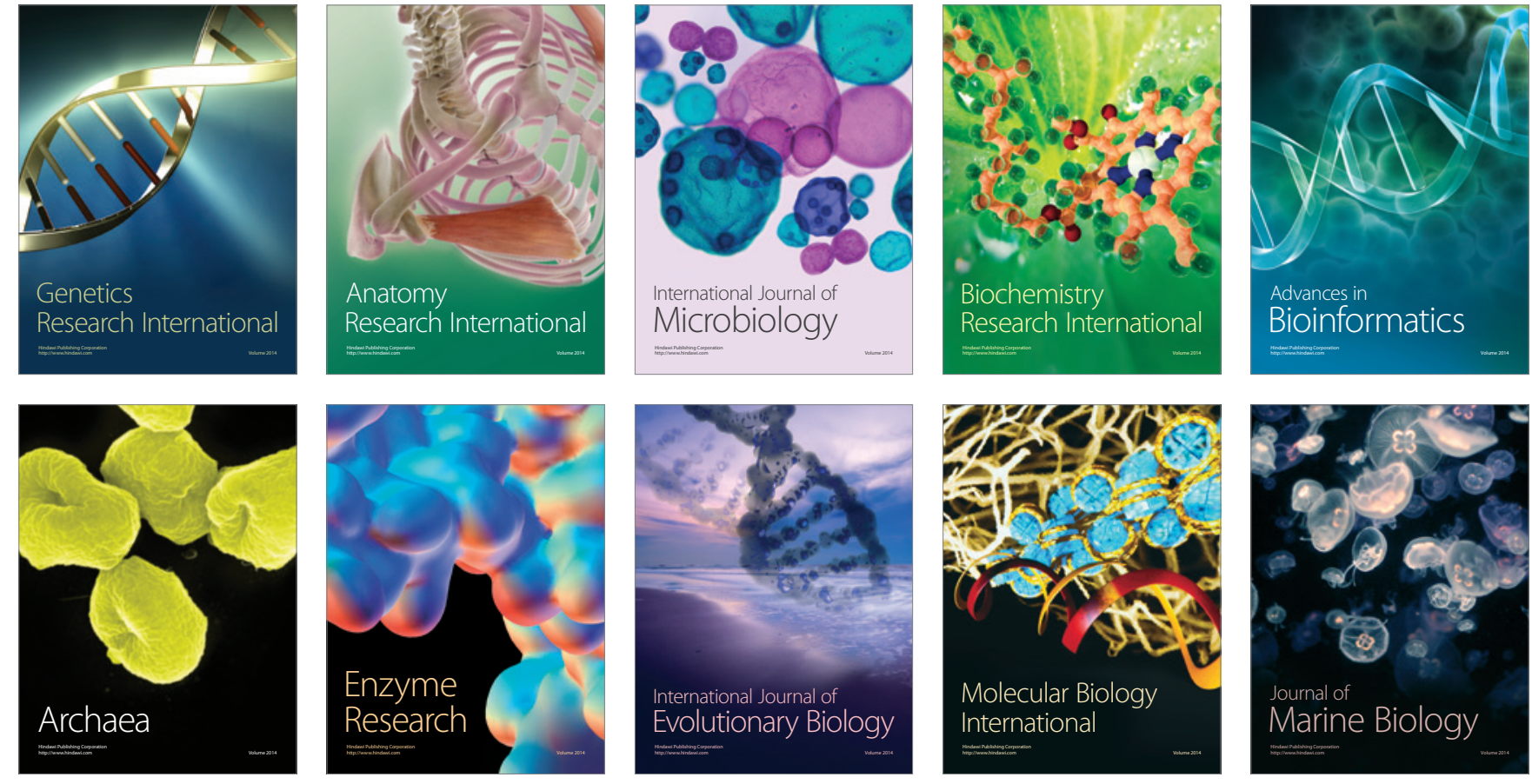